\title{
Medievalista
}

\section{Problemas metodológicos en el estudio del mundo rural andalusí}

Luis Gethsemaní Pérez Aguilar

\section{(2) OpenEdition}

\section{Journals}

\section{Edición electrónica}

URL: http://journals.openedition.org/medievalista/398

DOI: 10.4000/medievalista.398

ISSN: 1646-740X

\section{Editor}

Instituto de Estudos Medievais - FCSH-UNL

\section{Referencia electrónica}

Luis Gethsemaní Pérez Aguilar, «Problemas metodológicos en el estudio del mundo rural andalusí », Medievalista [En línea], 14 | 2013, Puesto en línea el 01 julio 2013, consultado el 01 mayo 2019. URL : http://journals.openedition.org/medievalista/398; DOI : 10.4000/medievalista.398

\section{(C) IEM}


Título: Problemas metodológicos en el estudio del mundo rural andalusí

Autor(es): Luis Gethsemaní Pérez Aguilar

Enquadramento Institucional: Becario FPU. Departamento de Prehistoria y Arqueología.

Facultad de Geografía e Historia. Universidad de Sevilla, España

Contacto: Iperez4@us.es

Fonte: Medievalista [Em linha]. №14, (Julho - Dezembro 2013). Dir. José Mattoso.

Lisboa: IEM.

Disponível em: http://www2.fcsh.unl.pt/iem/medievalista/

ISSN: 1646-740X

\section{Resumo}

Este artigo apresenta uma série de reflexões de carácter teórico-metodológico relativas ao estudo do povoamento rural medieval no Al-Andalus. Trata-se de colocar o acento tónico no hábito, existente entre muitos arqueólogos, de colocar, indiscriminadamente, etiquetas classificatórias a entidades populacionais, sem uma apurada base prévia, descritiva e sistemática dos arqueossítios identificados com vista à sua posterior classificação. Neste trabalho aborda-se, sobretudo, a problemática referente à documentação de alcarias. Este termo (Alcaria) deriva do Árabe, tratando-se na sua origem de uma palavra polissémica que apresenta algumas dificuldades quando se interpreta o registo arqueológico. Como alternativa, propõe-se um modelo classificatório descritivo e flexível que permita ordenar, arqueologicamente, os tipos de arqueossítios andaluzes.

Palavras-chave: Arqueologia medieval, prospecção arqueológica, povoamento andalus, ocupação rural, alcaria. 


\section{Abstract}

This paper collects some reflections about the theoretical and methodological framework related to the study of medieval rural settlements of Al-Andalus. We are intended to put a special stress on the bad habit, among many archaeologists, to put qualifier labels on population entities without a previous base rich, descriptive and systematic of the located sites to its further documentation. It deals primarily the problem concerning to the documentation of farmsteads (al-qurà). This term, that of farmstead (al-qarya), from the Arabic language, is originally a polysemous word that presents certain difficulties in interpreting the archaeological record. As an alternative we aim to propose a descriptive and flexible classification in order to realise a tipology of the andalusí sites.

Keywords: Medieval Archaeology, archaeological survey, andalusí settlement, rural site, farmstead (al-qarya).

\section{Problemas metodológicos en el estudio del mundo rural andalusí 1}

\section{Luis Gethsemaní Pérez Aguilar}

Nuestra preocupación por la denominada Arqueología del territorio nos ha llevado a plantearnos una serie de cuestiones y problemas de carácter teórico-metodológico que afectan a la praxis de dicha disciplina a la hora de estudiar el mundo rural andalusí. Quizás esta humilde aportación pueda resultar de algún provecho a futuros prospectores

\footnotetext{
${ }^{1}$ Este trabajo se enmarca dentro de las actividades del grupo "HUM-402: Historiografía y Patrimonio Andaluz" del Plan Andaluz de Investigación. Mostramos nuestro más sincero agradecimiento a R. Mérida Fernández, P. Albuquerque, J. Rodríguez Mellado, J. A. Salas Álvarez y M. Mesa Romero.
} 
y excavadores en las fases de documentación e interpretación del registro arqueológico al que se enfrenten. Así, en las líneas que siguen, se trata de poner de manifiesto que en la disciplina arqueológica se tiende a caer en el vicio de emplear constantemente etiquetas sin una reflexión previa sobre su significado y contenido para calificar tipos de yacimientos. Esto suele llevar a los profesionales a hablar de tales categorías de forma casi autómata, con los problemas técnicos que ello acarrea a la hora de aproximarnos a la comprensión del territorio.

\section{¿Alquerías en Al-Andalus?}

Si bien el término alquería ha sido tradicionalmente vinculado a la idea de una especie de núcleo de explotación agropecuaria similar a la villa romana o al cortijo moderno ${ }^{2}$, determinados autores han venido contemplándolo bajo una dimensión de unidad de poblamiento mayor, semejante a lo que podríamos entender como un poblado rural o aldea $^{3}$. El hecho de que tradicionalmente los prospectores hayan trabajado con sólo uno de los conceptos, por lo general bien con el de poblado-aldea bien con el de cortijada, ha viciado notablemente la investigación sobre el mundo rural andalusí. La tendencia de los arqueólogos ha sido la de no contemplar en el campo otro tipo de yacimientos que no sean alquerías, sin dejar claro en notables casos a qué entidad poblacional se están refiriendo bajo dicho término. En la literatura científica de prospecciones arqueológicas

${ }^{2}$ GÓMEZ, A.; PÉREZ, L. G. y RUIZ, E. - Historia de Tomares. De la Prehistoria Reciente a la Edad Contemporánea. Tomares-Sevilla: Aconcagua Libros, 2011, p. 144; SALAS, J. de la A. y MESA, M. "La Dehesa de Puñana: una alquería almohade en el sur del Aljarafe sevillano". Boletín Asociación Española de Amigos de la Arqueología. No 41 (2001), pp. 134-135.

3 ÁLVAREZ, M. - "La alcaria de Los Barrios: un testimonio de antigua población musulmana en El Campo de Gibraltar". Almoraima. No 9 (1993), p. 130; GARCÍA SANJUÁN, A. - "La reciente investigación arqueológica sobre el territorio onubense durante el periodo andalusí: una revisión crítica". Arqueología y Territorio Medieval. No 13.3 (2006), p. 23. GUICHARD, P. - "El problema de la existencia de estructuras de tipo feudal en la sociedad de Al-Andalus. El ejemplo de la región valenciana". In BONNASSIE, P. et al. - Estructuras feudales y feudalismo en el mundo mediterráneo (siglos X-XIII). Barcelona: Ed. Crítica, 1984, pp. 130-131; GUICHARD, P. - "Le probleme des structures agraries en Al-Andalus avant la conquete chretienne". In CABRERA, E. - Andalucía entre Oriente y Occidente (1236-1492). Actas del V Coloquio Internacional de Historia Medieval de Andalucía. Córdoba: Diputación Provincial, 1988, p. 164; MARTÍNEZ, A. - "Breves notas sobre la funcionalidad de las torres islámicas de la campiña de Córdoba”. Antiquitas. № 15 (2003), pp. 79-80; MARTÍNEZ, A. "La alquería, unidad de poblamiento básica en el al-Andalus rural". Boletín de la Asociación Provincial de Museos Locales de Córdoba. № 6 (2005), pp. 114; SEVILLA, L., et al. - "Poblamiento medieval en Castellar de la Frontera. Nuevas aportaciones”. Almoraima. No 29 (2003), p. 201. 
son abundantes las referencias a supuestas alquerías islámicas cuando se encuentran en un yacimiento algunos fragmentos de cerámica vidriada musulmana ${ }^{4}$, no teniéndose en consideración ni la cantidad o densidad de la misma ni su dispersión en el yacimiento. Algo parecido ocurría antaño respecto al fenómeno de la villa romana. Cuando se acudía a ciertas cartas arqueológicas se podía perfectamente apreciar un territorium repleto de villae en el que no se consideraba apenas la posibilidad de otro tipo de asentamientos. Si los arqueólogos dedicados al mundo romano han ido corrigiendo tal hecho, vemos cómo dentro de los trabajos de prospección arqueológica se sigue cometiendo este defecto de cara a la categorización de los yacimientos de época andalusí. Esto debería solventarse sobre la base de la información aportada por sitios arqueológicos de diversa índole documentados mediante excavación, pues esto nos permitiría hacer inferencias sobre la extensión de los mismos, las posibilidades en relación con su emplazamiento topográfico, así como los tipos de materiales constructivos y cerámicos o de cualquier otra naturaleza que son característicos de estos núcleos debido a su frecuente presencia. Ello resultaría de utilidad a la hora de enfrentarnos al estudio territorial del mundo rural de Al-Andalus, pues permitiría el discernimiento en actividades de prospección arqueológica entre distintos tipos de unidades de poblamiento. Si seguimos contemplando el rico mundo rural andalusí desde simples esquemas binomiales (husūn / al-qurà) difícilmente se podrán entender muchos matices socioeconómicos y religiosos o la jerarquización política del territorio y las fluidas relaciones entre las partes que lo componen ${ }^{5}$.

El término castellano alquería deriva de una palabra de origen árabe, al-qarya (al-qurà en plural), de carácter polisémico. Vemos por ejemplo cómo en el diccionario árabeespañol de F. Corriente la entrada qarya, pl. qurà, significa «aldea, caserío, pueblo» ${ }^{6}$;

\footnotetext{
${ }^{4}$ Cf. TAHIRI, A. - Agricultura y poblamiento rural en Sevilla durante la época `abâdî. Sevilla: Ayuntamiento de Sevilla, 2001, p. 39.

5 A día de hoy se sigue asumiendo la hipótesis sobre un predominio de asentamientos rurales de carácter colectivo tipo aldeas; sin embargo, y sin dejar de ser ello relevante, entendemos que para una mejor comprensión de la dinámica territorial andalusí se debería tratar de contemplar igualmente las relaciones existentes entre distintas modalidades de unidades: madīna / mudun ó madā 'in (ciudad / ciudades), munya / munà (almunia / almunias), ḥisn / ḥusūn (fortaleza / fortalezas), ribāṭ / ribātāat ó arbața (rábida/rábidas), $k \bar{u} j$ / akwāj (choza / chozas), manzil / manāzil (posada / posadas), etc.

${ }^{6}$ CORRIENTE, F. - Diccionario árabe-español. Madrid: Instituto hispano-árabe de cultura, 1977, p. 266.
} 
en el de J. Cortés «pueblo; aldea; ciudad pequeña; comunidad rural» ${ }^{7}$; y en el de M. G. Kaplanian se hace referencia tanto a aldeas, a pueblos como a villas ${ }^{8}$. P. Guichard esboza y perfila la noción que sobre el término se recoge en el diccionario árabe-francés de Kazimirski, comentando que la «idea es la de «lugar habitado» o, más precisamente, zona rural dotada de un poblamiento sedentario» ${ }^{9}$. Dicha ambigüedad puede igualmente inferirse en los textos árabes de la época estudiada ${ }^{10}$, y debe ser entendida como un rasgo derivado de la propia riqueza del idioma árabe, donde un mismo término puede significar cosas distintas en relación con la situación comunicativa en el que se use. Así, la palabra qarya puede designar una realidad poblacional u otra en función del contexto en la que se use.

De otro lado, si se comparan los distintos significados existentes entre la voz qarya y alquería se observa un claro fenómeno de disfunción semántica ${ }^{11}$ entre la palabra castellana y su étimo árabe ${ }^{12}$. La vigésima segunda edición del diccionario de la RAE recoge para la entrada alquería dos acepciones: «f. Casa de labor, con finca agrícola, típica del Levante peninsular. 2.- f. caserío (\| conjunto reducido de casas)» ${ }^{13}$.

Dada esta infranqueable situación, y teniendo en cuenta que no siempre se dispone de la documentación literaria suficiente ${ }^{14}$ como para poder contextualizar un yacimiento que presumiblemente podríamos catalogar como tal, se nos presenta la necesidad de trabajar con un concepto arqueológico de qarya. Por otra parte, y pese a las excelentes

${ }^{7}$ CORTÉS, J. - Diccionario de árabe culto moderno Árabe-Español. Madrid: Gredos, 2004 [1996], p. 900.

${ }^{8}$ KAPLANIAN, M. G. - Alhambra, diccionario Árabe-Español/Español-Árabe. Barcelona: Ed. Ramón Sopena, 1984, pp. 30, 570 y 726.

${ }^{9}$ GUICHARD, P. - Al-Andalus frente a la conquista cristiana. Los musulmanes de Valencia (siglos XIXIII). Madrid-Valencia: Ed. Biblioteca Nueva-Universitat de València, 2001, p. 247, nota 37.

${ }^{10}$ Cf. idem, pp. 247-250 y 253-254.

11 Así, puede decirse que la palabra castellana deriva evolutivamente del término árabe; sin embargo, conceptualmente son distintas a nivel semántico.

${ }^{12}$ GARCÍA SANJUÁN, A. - "La reciente investigación arqueológica sobre el territorio onubense durante el periodo andalusí: una revisión crítica”. Arqueología y Territorio Medieval. No 13.3 (2006), p. 24.

${ }^{13}$ R.A.E. - Diccionario de la lengua española. Tomo I. Madrid: Ed. Espasa Calpe, 2001, p. 123.

${ }^{14}$ Una rica aproximación desde la toponimia al fenómeno poblacional andalusí ha podido ser llevada a cabo en Mallorca, donde se han podido calcular porcentajes relativos a la distribución espacial de qurà y raḥāl. Véase BARCELÓ, M. - "Vísperas de feudales. La sociedad de Sharq al-Andalus justo antes de la conquista catalana". In MAÍLLO, F. - España, Al-Andalus, Sefarad: síntesis y nuevas perspectivas. Salamanca: Universidad de Salamanca, 1988, p. 103; y POVEDA, A. R. - "Introducción al estudio de la toponimia árabe-musulmana de Mayurqa según la documentación de los archivos de la Ciutat de Mallorca". Awraq. No 3 (1980), pp. 79-81 y 94-95. 
reflexiones de P. Guichard y de T. F. Glick ${ }^{15}$, resulta complicado apreciar a través del registro arqueológico aspectos referentes a los tipos de propiedad o posibles categorías fiscales y jurisdiccionales ${ }^{16}$. Ante tal necesidad, se acudió a la literatura arqueológica con el ánimo optimista de encontrar aquellas claves que permitieran guiar a pie de campo a la hora de poder distinguir este tipo de yacimientos y de caracterizarlos. El optimismo inicial se quebró al comprobarse cómo la amplia mayoría de los especialistas documentaban tales asentamientos, pero sin explicar en momento alguno qué criterios habían utilizado para definirlos como tal. Resultado de esta búsqueda infructuosa ha sido la tabla que se anexa a este trabajo, llena de interrogantes y de datos imprecisos que han sido entrecomillados, pues cualitativamente son aclaratorios pero cuantitativamente inexactos (fig. 1). Sí se ha de decir que no todos los autores clasifican los asentamientos que en la tabla se presentan como alquerías. Esta cautela se hace necesaria dado el estado actual de la investigación, y estamos totalmente de acuerdo con A. Malpica cuando afirma que «se hace necesario un análisis descriptivo» a la hora de abordar el estudio del paisaje en Al-Andalus ${ }^{17}$. Este mismo autor ha vuelto a reiterar de forma más reciente que en los trabajos sobre el mundo rural andalusí los arqueólogos «aún no han pasado de un primer nivel de reconocimiento de las realidades más elementales y carecemos, por lo demás, de actuaciones arqueológicas que permitan un conocimiento más denso de las alquerías» ${ }^{18}$. Para poder describir una realidad primero hay que conocerla, y a día de hoy desconocemos bastante cómo eran los distintos tipos de unidades poblacionales del mundo rural andalusí a nivel arqueológico ${ }^{19}$. Sin embargo, existen importantes trabajos que se apoyan en la documentación literaria cristiana a la

${ }^{15}$ Véase GLICK, T. F. - Paisajes de conquista. Cambio cultural y geográfico en la España medieval. Valencia: Universitat de València, 2007; GUICHARD, P. - "El problema de la existencia de estructuras de tipo feudal en la sociedad de Al-Andalus. El ejemplo de la región valenciana". In BONNASSIE, P. et al. - Estructuras feudales y feudalismo en el mundo mediterráneo (siglos X-XIII). Barcelona: Ed. Crítica, 1984, pp. 117-145; y GUICHARD, P. - "Le probleme des structures agraries en Al-Andalus avant la conquete chretienne". In CABRERA, E. - Andalucía entre Oriente y Occidente (1236-1492). Actas del V Coloquio Internacional de Historia Medieval de Andalucía. Córdoba: Diputación Provincial, 1988, pp. 161-170.

${ }^{16}$ Cf. BARCELÓ, M. - "Vísperas de feudales. La sociedad de Sharq al-Andalus justo antes de la conquista catalana". In MAÍLLO, F. - España, Al-Andalus, Sefarad: síntesis y nuevas perspectivas. Salamanca: Universidad de Salamanca, 1988, pp. 104-105.

${ }^{17}$ MALPICA, A.- "El paisaje del mundo rural andalusí. Bases descriptivas para su análisis". PH: Boletín del Instituto Andaluz del Patrimonio Histórico. No 27 (1999), p. 148.

${ }^{18}$ MALPICA, A. - "Un asentamiento fortificado en la frontera nazarí-castellana: Castril de la Peña". Studia histórica. Historia Medieval. No 24 (2006), p. 200.

${ }^{19}$ Vid nota 17. 
hora de poder hacernos una idea de cómo eran numerosos lugares que desde el horizonte mental de un cristiano bajomedieval eran considerados alquerías. Para ello pueden consultarse los numerosos trabajos de M. $\operatorname{Espinar}^{20}$.

Por tanto, estimamos de necesaria urgencia orientar las preocupaciones primero a la caracterización descriptiva del poblamiento andalusí para que luego, en una segunda fase, podamos proceder a la ardua y complicada tarea de etiquetar la realidad conocida. A la hora de aproximarnos al conocimiento del mundo rural de Al-Andalus entendemos que las variables con las que se ha trabajado en la tabla resultan de cierta utilidad por las razones que se irán exponiendo.

\section{Propuesta para la caracterización descriptiva del poblamiento rural andalusí}

El trabajo de E. L. Domínguez nos ha resultado, en parte, inspirador a la hora de hacer una propuesta de distinción descriptiva de yacimientos rurales andalusíes ${ }^{21}$. Antes de anotarla, se debe dejar bien claro el hecho de que el modelo que se plantea debe ser mejorado sobre la base de la praxis arqueológica, y que, como comenta A. Malpica, «lo ideal sería conseguir cierta secuencia evolutiva» del poblamiento, es decir, prestar atención a su desarrollo cronológico ${ }^{22}$. No se pretende ofrecer un nuevo orden de categorías, pues éstas ya fueron dadas por la sociedad andalusí, sino plantear una serie de nociones descriptivas que permitan luego discutir ante qué realidad nos encontramos. De momento, vemos oportuna la distinción, a nivel técnico, entre distintos tipos de sitios arqueológicos: A) Asentamiento rural de primer orden. Dentro de esta categoría podrían incluirse realidades arqueológicas semejantes a poblados, aldeas, así como

\footnotetext{
${ }^{20}$ Véase por ejemplo ESPINAR, M. - "La alquería de Mondújar: mezquita y rábitas, cementerios, barrios y otras estructuras urbanas y rurales". Anaquel de Estudios Árabes. No 11 (2000), pp. 277-294; ESPINAR, M. - "Noticias sobre la alquería de Leuxa, Aleuxa o Lojuela. Un despoblado medieval del Valle de Lecrín". In ESPINAR, M. y GARCÍA, M. M. - La ciudad medieval y su territorio. I: Urbanismo, sociedad y economía. Cádiz: Agrija Ediciones, 2009, pp. 49-70; y ESPINAR, M. y PADILLA, L. - "Nigüelas, una alquería musulmana del Valle de Lecrín: la mezquita y otros centros religiosos". In ESPINAR, M. y GARCÍA, M. M. - La ciudad medieval y su territorio. I: Urbanismo, sociedad y economía. Cádiz: Agrija Ediciones, 2009, pp. 71-94.

${ }^{21}$ DOMÍNGUEZ, E. L. - "La huella olvidada: Arqueología y territorio de la Marchena andalusí". In FERRER, E. - Arqueología en Marchena. El poblamiento antiguo y medieval en el valle medio del río Corbones. Sevilla: Universidad de Sevilla y Ayuntamiento de Marchena, 2007, pp. 189-242.

${ }^{22}$ Vid nota 17, p. 152.
} 
caseríos o pequeños lugares ocupados por una comunidad humana de escasa entidad demográfica entre otros; B) Asentamiento rural de segundo orden. Esta categoría queda circunscrita a pequeños yacimientos donde se percibe un claro predominio (no excluyente) de las actividades de explotación económica del entorno sobre aquellas de carácter ocupacional comunitario. En esta categoría podrían incluirse cortijadas (mâ̂āšir) o granjas (raḥăl); C) Asentamientos rurales de planta dispersa. Pueden ser el resultado de la combinación de diversas entidades poblacionales próximas e interrelacionadas funcionalmente entre sí o bien de una misma entidad cuya planta se encuentra sectorizada o fragmentada por ciertos ítems; y D) Sitios para el control territorial. Generalmente de carácter estatal, suelen encontrarse inmersos dentro de una red de asentamientos rurales como los anteriormente anotados. En la mayoría de los casos se trata de torres-atalayas (burūŷ), así como de castillos o recintos fortificados (husūn). Al ser sitios arqueológicos sobre los que existe una abundante literatura nos centraremos aquí en los tres anteriores.

Hechas estas observaciones generales, uno de los asentamientos documentados para el mundo andalusí que es bastante citado en la bibliografía es el del yacimiento de Bofilla en Bétera (Valencia) ${ }^{23}$. Este yacimiento, que en ningún momento asumimos como modelo axiomático, resulta de gran utilidad a la hora de caracterizar lo que hemos denominado como asentamientos rurales de primer orden, al encontrarse excavado casi en su totalidad, aunque también haremos uso de datos procedentes de otros yacimientos, como el de Villa Vieja en Calasparra (Murcia), La Mesa de Chiclana de la Frontera (Cádiz), El Castillejo de Los Guájares (Granada), Alcariais de Odeleite (Castro Marim, Faro), Alcaria Longa (Mértola, Beja), etc ${ }^{24}$. Llegados a este punto se debe aclarar una

${ }^{23}$ LÓPEZ, P. - La alquería islámica en Valencia. Estudio arqueológico de Bofilla. Siglos XI a XIV. Valencia, 1994.

${ }^{24}$ BOONE, J. L. - "The first two seasons of excavations at Alcaria Longa: A Caliphal - Taifal period rural settlement in the lower Alentejo of Portugal". Arqueologia Medieval. No 1 (1992), pp. 51-64; BOONE, J. L. - "The third season of excavations at Alcaria Longa". Arqueologia Medieval. No 2 (1993), pp. 111-125; CARVALHO DOS SANTOS, F. J. - "O povoado rural (Qarya) dos Alcariais de Odeleite".

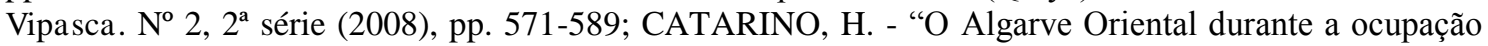
islâmica: Povoamento rural e recintos fortificados". Al-Ulya. Nº 6, (1997-98), 3 vols.; CRESSIER, P., MALPICA, A. y ROSSELLÓ, G. - "Analisis del poblamiento medieval de la costa de Granada: el yacimiento de "El Castillejo" y el valle del río de la Toba (Los Guájares)". In Actas del II Congreso de Arqueología Medieval Española. T. 2. Madrid: Delegación General de Cultura, 1987, pp. 149-160; FERNÁNDEZ, R. - Aporte de la Mesa (Chiclana de la Frontera, Cádiz) al estudio de la cerámica islámica del Gar al-Andalus. Cádiz: Universidad de Cádiz, 2007. Memoria de investigación; GARCÍA 
cuestión más. Si bien existen diferencias político-administrativas entre poblados, aldeas y caseríos, resulta tremendamente complejo observar dichas distinciones a nivel de prospección arqueológica. Podríamos perfectamente establecer la jerarquización basándonos en la extensión de los yacimientos. Sería lógico pensar que la diferencia, además de las político-administrativas, podría radicar en una cuestión de tamaño. Los poblados debieron ser de una mayor extensión que las aldeas, y éstas que los caseríos, con lo que el contingente humano de éstos pudo ser igualmente superior, con su posible reflejo en cuanto a la densidad de materiales, pero ¿dónde poner el límite entre unos yacimientos y otros a falta de textos o topónimos que nos permitan inferir tal realidad? Pensamos que resulta artificiosa una estandarización gradual de límites cerrados a nivel de hectáreas (por ejemplo, los poblados entre 10-5 ha, las aldeas entre 5-2 ha) y podría ser metodológicamente más correcto trabajar calculando aproximaciones en torno a medias matemáticas, ya que así se solventaría en parte el problema de dónde poner el límite entre una jerarquía u otra (¿por qué ponerlo entre poblados y aldeas en 5 y no en 6 ha?). Sin embargo en la bibliografía que se ha manejado apenas se recogen tales datos para la variable extensión (fig. 1), hecho que ha frustrado tal iniciativa ${ }^{25}$. Aún así, si se hubiera podido llegar a hacer tal ejercicio nos hubiésemos encontrado ante una disyuntiva semejante a la anterior: si la media nos marca 9 ha para los poblados y 3 ha

PORRAS, A. - La cerámica del poblado fortificado medieval de "El Castillejo” (Los Guájares, Granada). Granada: Ayuntamiento de Los Guájares, Athos-Pérgamos y Grupo de Investigación Toponímia, Historia y Arqueología del Reino de Granada, 2001; GARCÍA PORRAS, A. - "La distribución de productos cerámicos entre la época almohade y la nazarí. El caso de El Castillejo (Los Guájares, Granada)". Arqueoweb. Revista sobre Arqueología en Internet [Revista electrónica]. № 9, Vol.1 (2007). [Consultada a 29/01/2013]. http://www.ucm.es/info/arqueoweb/pdf/9-1/garcia.pdf; MALPICA, A., et al. - "Informe de la campaña de excavación sistemática del yacimiento medieval de El Castillejo (Los Guájares, Granada)". Anuario Arqueológico de Andalucía 1986. Vol. II (1987), pp. 487492; MALPICA, A. y CRESSIER, P. - "Informe sobre la campaña de excavación sistemática de "El Castillejo" (Los Guájares, provincia de Granada). Año 1989”. Anuario Arqueológico de Andalucía 1989. Vol. II (1991), pp. 287-289; POZO, I. - "La alquería de Villa Vieja (Calasparra, Murcia)". In BAZZANA, A. y HUBERT, E. - Castrum 6. Maisons et espaces domestiques dans le méditerranéen au Moyen Âge. Rome-Madrid: École Française de Rome y Casa de Velázquez, 2000, pp. 165-175. RAMOS, J. et al. - "La campaña de excavación de 1.998. Estructuras y áreas de actividad". In RAMOS, J. et al. Excavaciones arqueológicas en La Mesa (Chiclana de la Frontera, Cádiz). Campaña de 1998. Aproximación al estudio del proceso histórico de su ocupación. Chiclana de la Frontera: Ayuntamiento de Chiclana de la Frontera y Fundación VIPREN, 1999, pp. 41-76; y RAMOS, J., et al. - "La ocupación campesina islámica en La Mesa", en RAMOS. J. et al. - Excavaciones arqueológicas en La Mesa (Chiclana de la Frontera, Cádiz). Campaña de 1998. Aproximación al estudio del proceso histórico de su ocupación. Chiclana de la Frontera: Ayuntamiento de Chiclana de la Frontera y Fundación VIPREN, 1999, pp. 291-307.

${ }^{25}$ Cf. GARCÍA SANJUÁN, A. - "La reciente investigación arqueológica sobre el territorio onubense durante el periodo andalusí: una revisión crítica". Arqueología y Territorio Medieval. No 13.3 (2006), pp. $22-24$. 
para las aldeas ¿dónde meteríamos un yacimiento de 5 o 6 ha? Planteada la problemática, y a menos que en el futuro se excaven unidades de estas tres entidades de asentamientos rurales de primer orden identificables mediante textos, topónimos o algún otro tipo de clara evidencia, pensamos que lo más cómodo es trabajar con un concepto unificado en el que se asuman sendas realidades. Se debe entender que aquellos sitios arqueológicos de mayor extensión se aproximan a la probabilidad de ser clasificados como poblados, que aquellos de una menor envergadura quizás gozaran de una categoría aldeana, y que aquellos otros de escaso tamaño podrían tratarse de caseríos. Sin embargo ello no debe ser entendido en sentido axiomático, sino como un modus operandi cómodo a la hora de trabajar en las prospecciones arqueológicas. Dicho todo esto, las características que podemos inferir a partir del yacimiento de Bofilla y otros para las variables que se han anotado son las siguientes:

A) Extensión. El sitio arqueológico de Bofilla consta de una zona de tendencia rectangular con una extensión aproximada de algo menos de 4 ha para el siglo XI d.C. ${ }^{26}$. El asentamiento presenta fundamentalmente dos partes. La primera de ellas se vincula al sistema defensivo del mismo, enmarcando aproximadamente unas 2,48 ha de superficie interior. La segunda comprende la superficie edificada por viviendas privadas y construcciones de carácter comunitario de 1,4 ha. Por otro lado se encuentra el caso del yacimiento de Villa Vieja, parcialmente excavado. Éste constituye una realidad arqueológica que contrasta notablemente respecto a Bofilla en cuanto a la variable extensión, pues, pese a que sólo se han excavado 0,17 ha, la superficie del yacimiento ha sido estimada en 0,55 ha $^{27}$. Se tiene también el ejemplo de El Castillejo de Los

\footnotetext{
${ }^{26}$ Respecto a la cuestión cronológica y de extensión deben tenerse en cuenta dos matizaciones. La primera de ellas viene de la mano de P. Guichard, quien, a partir de las intervenciones arqueológicas que efectuó en 1972 en el sitio, sostiene que la estratigrafía revela una ocupación en los siglos X y XI d.C. para los niveles VIIb y IX. Para ello véase GUICHARD, P. - "Primer informe sobre las excavaciones realizadas en Torre Bufilla, Betera. (Valencia)". Noticiario Arqueológico Hispánico. Arqueología. No 4 (1976), pp. 607-643; y GUICHARD, P. - "Trente cinq ans après, faut-il rouvrir le dossier "Bufilla"?. In GÓMEZ, S. - Al-Ândalus. Espaço de mudança. Balanço de 25 anos de história e arqueologia medievais. Homenagem a Juan Zozaya Stabel-Hansen. Mértola: Campo Arqueológico de Mértola, 2006, pp. 119121. La segunda matización es añadida por el propio P. López, quien comenta que para la segunda mitad del siglo XII d.C. la superficie del yacimiento se redujo a unas 2,6 ha. Véase LÓPEZ, P. - La alquería islámica en Valencia. Estudio arqueológico de Bofilla. Siglos XI a XIV. Valencia, 1994, p. 189.

${ }^{27}$ POZO, I. - "La alquería de Villa Vieja (Calasparra, Murcia)". In BAZZANA, A. y HUBERT, E. Castrum 6. Maisons et espaces domestiques dans le méditerranéen au Moyen Âge. Rome-Madrid: École Française de Rome y Casa de Velázquez, 2000, p. 167.
} 
Guájares (Granada), con una extensión que ronda las $1,56 \mathrm{ha}^{28}$. En cuanto a sitios documentados en actividades de prospección se observa que de los pocos yacimientos de los que se dispone de datos más o menos fiables, hay unos cuya extensión gira en torno a 1 ha (El Cruce, Los Eucaliptos), otros que lo hacen en torno a las 2 ha (Purchena, Látigo de Monteagudo III) y otros que superan las 4 ha (Los Olivos, Olivar del Molino). Entre estos lugares se puede incidir en dos casos que resultan sustancialmente distintos. El primero de ellos probablemente podría tratarse de un poblado mientras que el otro quizás pudiera definirse como aldea. Tenemos por un lado el yacimiento del Olivar del Molino, en Castellar de la Frontera (Cádiz), que presenta una dispersión de sus materiales (sobre todo cerámica de mesa-cocina andalusí y restos constructivos) que ronda en torno a las $10 \mathrm{ha}^{29}$. Por otra parte nos encontramos con el sitio arqueológico del Látigo de Monteagudo III, que aun no siendo de los más pequeños entre los citados lo hacemos destacar precisamente por su carácter inédito. Éste se trata de un yacimiento localizado por J. Rodríguez en su actividad de prospección arqueológica en el término municipal de Sanlúcar de Barrameda (Cádiz). El sitio se encuentra emplazado en un pequeño cerro junto a Las Marismas del Guadalquivir. Se caracteriza por una densidad de materiales alta en la que la desproporción entre la cerámica de mesa-cocina y la de almacenaje es acusada y en favor de las primeras. La cronología dada al yacimiento por su prospector es de época almohade (s. XII), con una dispersión de los materiales que ronda las 2,10 ha ${ }^{30}$. Sería de notable interés científico poder comparar, a partir de futuras excavaciones, la relación existente entre las dispersiones de materiales de yacimientos prospectados y la extensión de esos mismos sitios una vez excavados.

B) Emplazamiento. Si se observa la tabla anexa (fig. 1), se puede distinguir, grosso modo, una serie de hechos generales que tienden a reiterarse de forma casi constante y que pueden considerarse determinantes de cara a la comprensión de muchos

${ }^{28}$ GARCÍA PORRAS, A. - "La distribución de productos cerámicos entre la época almohade y la nazarí. El caso de El Castillejo (Los Guájares, Granada)". Arqueoweb. Revista sobre Arqueología en Internet [Revista electrónica]. N $\quad N^{\text {o }}$ 9, Vol.1 (2007), p. 2. [Consultada a 29/01/2013]. http://www.ucm.es/info/arqueoweb/pdf/9-1/garcia.pdf.

29 SEVILLA, L. et al. - "Poblamiento medieval en Castellar de la Frontera. Nuevas aportaciones". Almoraima. No 29 (2003), p. 205.

${ }^{30}$ RODRÍGUEZ, J. - Revisión de las cartas arqueológicas del término municipal de Sanlúcar de Barrameda: una puesta al día. Sevilla: Universidad de Sevilla, 2010. Trabajo Fin de Máster de Arqueología, inédito, pp. 244-247. 
asentamientos rurales en $\mathrm{Al}$-Andalus. Se tratan de yacimientos localizados en una elevación cuyas cotas pueden variar en función de las características geográficas del entorno del que forman parte, siendo también normal el aprovechamiento de la cercanía de un barranco o zona escarpada o de acentuada pendiente, ya que así se minimiza el esfuerzo invertido en la defensa del sitio. La ubicación elevada de tales lugares permite tener un control estratégico sobre el territorio circundante, funcionando igualmente las características topográficas del terreno como un rasgo fundamental en la defensa pasiva. Hechos determinantes los constituyen tanto la riqueza acuífera y agrícola del entorno como la cercanía a vías de comunicación. Para la mejor comprensión de muchos asentamientos debe igualmente tenerse en cuenta otras variables que por distintas razones no se han podido contemplar en la tabla, pero que sin duda hubieran ayudado a enriquecerla analíticamente hablando, como la navegabilidad de ríos cercanos, los tipos de suelos, la presencia de salinas, canteras o minas en el territorio próximo, así como el posible carácter ganadero o pastoril de los caminos inmediatos. A veces se podrán enfatizar o verificar determinados elementos que vienen a explicar el emplazamiento de los sitios con elementos de cultura material localizados intra-site, como puede ser el caso del hallazgo de escorias de metal, abundantes huesos de animales, etc ${ }^{31}$. Pensamos que debe prestarse igualmente atención a lugares que se salen de la norma general, tales como Torre de Medalla, Torre Negra, Molino de la Venta o Purchena, y que por alguna razón se emplazan en sitios llanos o casi llanos. Aunque intuimos la razón de ser de estos yacimientos, la escasez de datos ha impedido nuevamente poder evaluar este hecho, que debe tener evidentemente alguna explicación lógica.

C) Tipos de materiales constructivos. Esta variable no sólo debería ser definida en cuanto a variedad de materiales, sino también en relación con la densidad de los

\footnotetext{
31 Un magnífico ejemplo de esto último puede constatarse en el sitio arqueológico de Alcariais de Odeleite, asentamiento andalusí volcado hacia actividades agropecuarias donde se han hallado espacios domésticos y otras estancias interpretadas como establos y corrales, así como un considerable número de huesos de animales en el proceso de excavación. Dicho material osteológico cuenta con un interesante estudio zooarqueológico que ha permitido evidenciar el aprovechamiento de especies como conejos, vacas, ovicápridos y, en menor medida, cérvidos, pescado y gallináceas. Esta misma tendencia puede apreciarse entre los huesos documentados en Alcaria Longa. Véase BOONE, J. L. - "The third season of excavations at Alcaria Longa". Arqueologia Medieval. No 2 (1993), pp. 115 y 124; CARVALHO DOS SANTOS, F. J. - "O povoado rural (Qarya) dos Alcariais de Odeleite”. Vipasca. No 2, 2ª série (2008), pp. 571-589 y PEREIRA, V. - "Alcariais de Odeleite - Perspectiva zooarqueológica". In Actas do V Encontro de Arqueologia do Sudoeste Peninsular, (2012), pp. 821-830.
} 
mismos, hecho que no hemos podido insertar en nuestra tabla (fig. 1), pero que debería ser igualmente tenido en cuenta. Lo cierto es que las sociedades preindustriales tienden a reutilizar con gran frecuencia los recursos constructivos que se prestan a ello, de ahí que sea frecuente el uso de viejos sitios como canteras de las que obtener materiales para nuevas obras. Esto, como se habrá podido deducir, puede llegar a afectar a la percepción que el prospector pueda llegar a tener sobre determinado yacimiento en superficie, y es un inconveniente que debe ser asumido. Dicho todo ello, en el caso de Bofilla el material constructivo más abundante suele ser el tapial, problemático de cara a su localización en superficie por cuestiones de conservación asociadas a labores de arado. En los asentamientos rurales andalusíes lo frecuente es el hallazgo de mampostería, pudiéndose incluso encontrar en determinados lugares evidencias de muros arrasados o restos de los mismos. También pueden llegar a localizarse tejas (bien de techumbres de casas, bien de cubiertas de tumbas) ${ }^{32}$. Por otra parte, el ladrillo constituye un elemento de presencia restringida en cuanto a densidad, en parte por su coste de producción. En la literatura al uso suele ser frecuente la referencia a tégulas e ímbrices, e incluso a sillares de época romana que fueron reutilizados. Ante tal hecho nos surge la cuestión, ¿cómo es posible sostener en actividades de prospección que ciertos materiales de momentos anteriores fueron reutilizados en un yacimiento medieval? Entendemos que en muchos casos es casi imposible poder determinar tal hecho, sobre todo cuando nos encontramos ante sitios arqueológicos que presentan distintas fases o periodos de ocupación. Sin embargo, si el lugar estudiado se caracteriza por tener algunos materiales constructivos de épocas pretéritas dentro de un mare magnum de cultura material propia del Medievo (cerámica por lo general), es muy probable que los primeros respondan a una naturaleza de segundo uso. Ello debe dar lugar a una doble reflexión: 1) Posiblemente muchos supuestos yacimientos de época romana de escasa envergadura no deban contarse como sitios arqueológicos de dicho periodo, sino que se traten de elementos constructivos reutilizados dentro de un yacimiento medieval; 2) Muchos de los supuestos materiales romanos reutilizados en asentamientos andalusíes no deberían ser considerados como tales si en el mismo yacimiento se ha detectado una considerable presencia de restos cerámicos romanos.

\footnotetext{
${ }^{32}$ En el yacimiento de Alcariais de Odeleite se aprecia cómo el uso de tejas de media caña también puede emplearse en la construcción de los hogares de cocina. Véase CARVALHO DOS SANTOS, F. J. - "O povoado rural (Qarya) dos Alcariais de Odeleite". Vipasca. No 2, $2^{\mathrm{a}}$ série (2008), p. 580.
} 
Dejando este tema a un lado, en los asentamientos rurales de Al-Andalus, sobre todo en aquellos sometidos a excavación, pueden llegar a encontrarse algún tipo de evidencia que apunte hacia la presencia de hornos domésticos, como tierra rubefactada o algún tipo de piedra refractaria, caso del rodeno, etc. Se tiene constancia literaria de que en asentamientos como los de Nigüela o Leuxa se llevaban a cabo actividades artesanales orientadas a la producción de materiales constructivos ${ }^{33}$, con lo que no debería extrañar la posibilidad de documentar en los aledaños a tales yacimientos, en lugares aptos para ello, la presencia de tejares que podrían localizarse en superficie a partir de los residuos y fallos de cocción que de éstos se derivan.

D) Tipos de materiales cerámicos. Pese a su importante presencia cuantitativa en los sitios arqueológicos, los conjuntos de materiales cerámicos tradicionalmente han acaparado la atención de los investigadores en relación con los atributos individuales de las piezas, es decir, las características morfológicas, funcionales y tecnológicas de cada una de ellas, ignorándose o marginándose otra serie de atributos que permiten exprimir el potencial de la cerámica de cara a los estudios del paisaje dentro de un marco analítico contextual ${ }^{34}$. A la hora de categorizar un asentamiento humano en prospección arqueológica uno de los principales elementos a tener en cuenta debería ser la variedad estadística de tipos cerámicos que en un lugar aparecen, así como la densidad y la dispersión de los mismos en el yacimiento. Estas variables deben conjugarse con otras de las aquí anotadas, no debiéndose emplear ninguna de ellas de forma aislada, sino en combinación con las demás. Por ello nos mostramos de acuerdo con A. García Porras cuando apunta hacia la importancia de contemplar «la frecuencia en que aparecen cada una de las series existentes, cada uno de los distintos conjuntos funcionales o vajillas, y las relaciones que mantienen entre ellos», pues ello nos puede ayudar a precisar de una forma más coherente ante qué tipo de yacimiento, o parte del mismo, nos encontramos,

\footnotetext{
${ }^{33}$ Cf. ESPINAR, M. - "Noticias sobre la alquería de Leuxa, Aleuxa o Lojuela. Un despoblado medieval del Valle de Lecrín”. In ESPINAR, M. y GARCÍA, M. M. - La ciudad medieval y su territorio. I: Urbanismo, sociedad y economía. Cádiz: Agrija Ediciones, 2009, p. 51; y ESPINAR, M. y PADILLA, L. - "Nigüelas, una alquería musulmana del Valle de Lecrín: la mezquita y otros centros religiosos". In ESPINAR, M. y GARCÍA, M. M. - La ciudad medieval y su territorio. I: Urbanismo, sociedad y economía. Cádiz: Agrija Ediciones, 2009, p. 92.

${ }^{34}$ CARVAJAL, J. C. - "Cerámica y paisaje. Posibilidades y expectativas en la época andalusí-castellana". In JIMÉNEZ, M. y MATTEI, L. - El paisaje y su dimensión arqueológica. Estudios sobre el sur de la Península Ibérica en la Edad Media. Granada: Alhulia, 2010, pp. 161-168.
} 
ya que son indicadores vestigiales de actividades humanas ${ }^{35}$. Más o menos en la misma línea, J. C. Carvajal ha comentado más recientemente que la cerámica debería entenderse como «un objeto «vivo», es decir, en su contexto de uso y producción [...]. [...] debería estar en la mente de todo investigador que una parte fundamental del objeto arqueológico es su pasado como producto y objeto de consumo» ${ }^{36}$. Así, en Bofilla se ha cuantificado un total de 24.000 fragmentos, siendo la cerámica común no barnizada ni decorada la que goza de una mayor presencia en sus distintos tipos y formas (18.000 fragmentos) ${ }^{37}$. En los asentamientos rurales de primer orden puede llegar a predominar sobre todo la cerámica de mesa y de cocina (marmitas-ollas, cazuelas, cuscuseras-coladores, discos-placas para hornear, alcadafes-lebrillos, ataifores y jofainas, jarritas y jarritos, copas-tazas, botellitas, redomas, anafes y tapaderas) sobre la de almacenaje (tinajas, jarros y jarras, orzas, tapaderas), siendo también destacable la presencia de candiles. En cambio, en los asentamientos rurales de segundo orden la desproporción entre los recipientes de almacenaje y los de cocina-mesa debió ser menor. Ello radica fundamentalmente en el hecho de que, a nivel temporal, en un poblado, aldea o caserío el contingente humano y la cacharrería propia del ámbito doméstico debían ser más importantes cuantitativamente que los de una cortijada o granja. Si bien se carece de este tipo de estudios para la amplia mayoría de los asentamientos rurales que se han recogido en nuestra tabla (fig. 1), ello ha podido ser constatado, por ejemplo, en el caso del asentamiento rural de primer orden de La Mesa, donde en los distintos estudios arqueológicos efectuados se ha podido verificar un claro predominio de la cerámica de cocina-mesa sobre la de almacenaje $\mathrm{e}^{38}$ : el primer grupo

35 GARCÍA PORRAS, A. - La cerámica del poblado fortificado medieval de "El Castillejo" (Los Guájares, Granada). Granada: Ayuntamiento de Los Guájares, Athos-Pérgamos y Grupo de Investigación Toponímia, Historia y Arqueología del Reino de Granada, 2001, pp. 415-416.

${ }^{36}$ Vid nota 34, p. 163.

37 Anotamos las cantidades ofrecidas por LÓPEZ, P. - La alquería islámica en Valencia. Estudio arqueológico de Bofilla. Siglos XI a XIV. Valencia, 1994. La información cuantitativa aportada por las intervenciones de P. Guichard $(1976,611)$ resulta indicativa, pero no estrictamente aclaratoria, pues en su informe solamente se hace referencia a la presencia de «un abundante material cerámico de más de 2.500 fragmentos», no concretándose cuántos más. Más interesante resulta el hecho resaltado por dicho autor sobre «un gran predominio de la cerámica vulgar, bizcochada o barnizada». Véase GUICHARD, P. "Primer informe sobre las excavaciones realizadas en Torre Bufilla, Betera. (Valencia)". Noticiario Arqueológico Hispánico. Arqueología. № 4 (1976), pp. 611.

${ }^{38}$ Para ambos casos se ofrecen dos cantidades. Las primeras de ellas han sido obtenidas de la obra de RAMOS, J., et al. - "La ocupación campesina islámica en La Mesa", en RAMOS. J. et al. - Excavaciones arqueológicas en La Mesa (Chiclana de la Frontera, Cádiz). Campaña de 1998. Aproximación al estudio del proceso histórico de su ocupación. Chiclana de la Frontera: Ayuntamiento de Chiclana de la Frontera y Fundación VIPREN, 1999, pp. 291-307. Se observa un error en el cálculo de los porcentajes, ya que si 
funcional de recipientes viene a quedar representado por un porcentaje que oscila entre el $71,81 \mathrm{y}$ el $80 \%$, mientras que el segundo grupo gira en torno al 30,27 y al $8 \%$. También se cuenta con el caso de El Castillejo, donde sobre un total de 422 piezas identificadas nos encontramos que el $57,8 \%$ se trata de cerámica de mesa-cocina, mientras que el 20,9\% son recipientes destinados al almacenamiento ${ }^{39}$. Esta lógica se percibe igualmente en otro tipo de ámbitos poblacionales, tal y como se ha visto por ejemplo en la ciudad de Fīsāna Faysāna (Medina Sidonia, Cádiz) ${ }^{40}$, de ahí la necesidad de contrastar esta variable con las demás, así como con datos de otra naturaleza. Tras haberse anotado estos casos debe insistirse una vez más que no se trata de una cuestión de presencia/ausencia, sino de proporciones y distribuciones de los tipos funcionales cerámicos. Arriba se ha hecho referencia aquellos sitios de los que se dispone de una información cuantitativa relativamente fiable. Sin embargo, si observamos la tabla anexa (fig. 1) podrá constatarse cómo hay ciertos yacimientos que, según este criterio, también podrían ser clasificados como asentamientos rurales de primer orden, si bien desde una base más cualitativa: Alcariais de Odeleite o Látigo de Monteagudo son claros ejemplo de ello. Un yacimiento peculiar en lo que a proporciones se refiere lo constituye Alcaria Longa. Si se hace caso a las cifras que ofrece su excavador para la tercera campaña arqueológica, se tiene un total de 5196 fragmentos cerámicos, representando el repertorio de cocina-mesa un 49,83\% y el de almacenaje un 50,17\%, siendo ligeramente superior al primero ${ }^{41}$. Si bien desconocemos tales estadísticas

sumamos los de la cerámica de cocina-mesa y los de almacenamiento tenemos un total de 102,08\%. Si a ello se añade el porcentaje de los candiles la cifra aumenta a 102,35\%. Las segundas cantidades las hemos estimado nosotros, no sin dificultad, a partir del trabajo de FERNÁNDEZ, R. - Aporte de la Mesa (Chiclana de la Frontera, Cádiz) al estudio de la cerámica islámica del Gar al-Andalus. Cádiz: Universidad de Cádiz, 2007. Memoria de investigación. Si se procede a realizar la suma de los porcentajes se obtiene un total de $88 \%$, correspondiéndose el restante a otros tipos cerámicos que aquí no nos interesan.

${ }^{39}$ GARCÍA PORRAS, A. - La cerámica del poblado fortificado medieval de "El Castillejo" (Los Guájares, Granada). Granada: Ayuntamiento de Los Guájares, Athos-Pérgamos y Grupo de Investigación Toponímia, Historia y Arqueología del Reino de Granada, 2001, pp. 437-440; y GARCÍA PORRAS, A. - "La distribución de productos cerámicos entre la época almohade y la nazarí. El caso de El Castillejo (Los Guájares, Granada)". Arqueoweb. Revista sobre Arqueología en Internet [Revista electrónica]. No 9, Vol.1 (2007). [Consultada a 29/01/2013]. http://www.ucm.es/info/arqueoweb/pdf/91/garcia.pdf, p. 6.

40 ABELLÁN, J. y CAVILLA, F. - "Fīsāna Faysāna o Q.Y. Sāna, un despoblado altomedieval en la cora de Šadūna”. Al-Andalus - Magreb: Estudios árabes e islámicos. No 1 (1993), pp. 25-26.

${ }^{41}$ Dichos porcentajes han sido reajustados por nosotros, ya que las cifras exactas ofrecidas por su autor no sumaban $100 \%$. Cf. BOONE, J. L. - "The third season of excavations at Alcaria Longa". Arqueologia Medieval. $\mathrm{N}^{\mathrm{o}} 2$ (1993), pp. 122 y 124. Por otra parte debemos aclarar que, comparando los datos del texto 
aplicadas a las dos primeras campañas de excavaciones, hecho que podría modificar tales resultados, se debe contemplar la patente necesidad de almacenaje que presentó el citado asentamiento.

E) Otro tipo de evidencias materiales. Lejos de tratarse de una especie de cajón de sastre donde todo cabe, este campo o variable puede resultar en numerosas ocasiones bastante aclaratorio para determinar ante qué tipo de asentamiento nos encontramos. En él se puede incluir una serie de elementos muebles que por lo general suelen ser poco frecuentes en superficie, tales como monedas, agujas metálicas, llaves, anillos, clavos, espátulas, hebillas, sortijas, teselas, útiles de hierro, escorias de metal, piedras de molino, fragmentos de vidrio, huesos, etc. En relación con los elementos inmuebles debe de prestarse atención a tres frentes. El primero de ellos se refiere a la presencia o ausencia de antiguos sistemas hidráulicos en el entorno del yacimiento. Éstos han sido bien estudiados por la disciplina arqueológica en Andalucía oriental, el Levante peninsular y Baleares. Pueden componerse de restos de acequias, de puntos de captación de agua en ríos, manantiales o del subsuelo (pozos con posibles norias), albercas o estanques para su almacenamiento y distribución, molinos, aljibes, etc ${ }^{42}$. De otro lado, aún no siendo un elemento indispensable, tal y como sucede con el cerco amurallado ${ }^{43}$, cabe la posibilidad de que la realidad arqueológica de un asentamiento rural de primer orden quede señalada en el paisaje mediante la presencia de una torre defensiva $($ bur $\hat{y})$ o restos de la misma ${ }^{44}$, como por ejemplo pasa en los casos de Bofilla, La Mesa (Chiclana

con los dibujos arqueológicos del mismo hemos interpretado large jars dentro del grupo de cerámica de almacenaje, pudiéndo traducirse dicha expresión al castellano bajo la denominación de tinajas.

${ }^{42}$ Cf. KIRCHNER, H. - "Observaciones a propósito de la hidráulica andalusí". In MORILLA, J., GÓMEZ, J. y CRESSIER, P. - Impactos exteriores sobre el mundo rural mediterráneo: del Imperio romano a nuestros días. Madrid: Ministerio de Agricultura, Pesca y Alimentación, 1997, pp. 139-161.

${ }^{43}$ T. G. Glick nos anota la propuesta de K. W. Butzer para los asentamientos rurales de la zona de Castellón, quien entiende la fortificación de los mismos en el siglo XII como respuesta a la amenaza cristiana. Véase GLICK, T. F. - Paisajes de conquista. Cambio cultural y geográfico en la España medieval. Valencia: Universitat de València, 2007, p. 41.

${ }^{44}$ A. Martínez, siguiendo la propuesta de F. Sánchez Villaespesa, anota que gran parte de estas torres son de momentos tardíos, próximos a la conquista castellana. La cercanía del enemigo incitaría a las comunidades rurales a desarrollar algún tipo de sistema defensivo para autoprotegerse y controlar

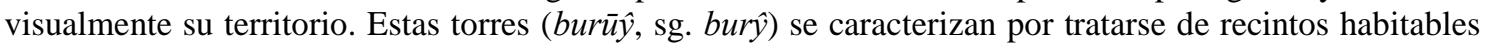
de planta cuadrada, quedando siempre vinculadas a tales asentamientos humanos. Las atalayas, en cambio, suelen ser de planta circular, más pequeñas y no son habitables. Tampoco tienen por qué formar parte de un núcleo de población, pudiendo quedar dispersas por el territorio en sitios claves de cara a su control estratégico. Véase MARTÍNEZ, A. - "Breves notas sobre la funcionalidad de las torres islámicas de la campiña de Córdoba". Antiquitas. Nº 15 (2003), pp. 80-82; y MARTíNEZ, A. - "La alquería, unidad 
de la Frontera, Cádiz), Benimina (Benizalón, Almería), Alhabia (Alcudia de Monteagud, Almería), Niguielas (Valle de Lecrín, Granada), los Álamos y Torre de la Horra (San Roque, Cádiz) (fig. 1) ${ }^{45}$. Por tanto, se debe tener en cuenta si existen evidencias que apunten hacia algún tipo de sistema defensivo (murallas, torres) y la relación espacial de éste respecto al poblado. Lo lógico es pensar que la presencia de este tipo de elementos apunte hacia un asentamiento rural de primer orden, aunque resulta complicado poder discernirlo sólo a través de un elemento aislado. Tampoco debemos caer en la tentación de vincular una torre a una entidad de poblado o aldea asociado a ella, ya que podría darse el caso de caseríos que para su defensa levantaran una de éstas. A veces se pueden encontrar torres empotradas en edificios modernos, con lo que éstos deberán ser examinados en caso de su existencia. Si bien resulta poco frecuente, es posible que el sitio carezca de un cerco amurallado y que la defensa se organice sobre la base de delimitar el perímetro del asentamiento a partir de la unión paramental de unidades domésticas, tal y como se ha propuesto para el caso de Alcaria Longa $^{46}$. De otra parte, deben ser tenidas en cuenta noticias o hallazgos de posibles silos en el territorio, incluso aquéllos dados por prehistóricos en excavaciones antiguas y que en ciertos casos han resultado ser en realidad de cronología medieval, como por ejemplo ocurre con varios de los ejemplares del yacimiento sevillano de Estacada de Alfaro, en La Puebla del Río ${ }^{47}$.

Lo deseable sería que estas líneas generales que se han ido proponiendo se fueran matizando en el futuro sobre la base de intervenciones arqueológicas y de las distintas problemáticas y dificultades inherentes a ellas. Pensamos que este esquema descriptivo

de poblamiento básica en el al-Andalus rural". Boletín de la Asociación Provincial de Museos Locales de Córdoba. N 6 (2005), pp. 119-121.

${ }^{45}$ Para los tres últimos casos véanse ESPINAR, M. y PADILLA, L. - "Nigüelas, una alquería musulmana del Valle de Lecrín: la mezquita y otros centros religiosos". In ESPINAR, M. y GARCÍA, M. M. - La ciudad medieval y su territorio. I: Urbanismo, sociedad y economía. Cádiz: Agrija Ediciones, 2009, pp. 71-94. y GOZALBES, C. - "Nuevas alquerías medievales en El Campo de Gibraltar: Granados, Álamos, Patraina, Torre de la Horra y Tábanos". Almoraima. № 29 (2003), pp. 261-272..

${ }^{46}$ BOONE, J. L. - "The first two seasons of excavations at Alcaria Longa: A Caliphal - Taifal period rural settlement in the lower Alentejo of Portugal". Arqueologia Medieval. No 1 (1992), p. 56.

${ }^{47}$ Cf. CARRIAZO, J. de M. - Protohistoria de Sevilla. Sevilla: Ayuntamiento de Sevilla, 1974, pp. 160163; ESCACENA, J. L. - "Yacimientos arqueológicos de época medieval en el flanco oriental del Aljarafe". Actas del II Congreso de Arqueología Medieval Española. T. 2. Madrid: Delegación General de Cultura, 1987, p. 586; y SALAS, J. de la A. y MESA, M. - Prospección arqueológica superficial del término municipal de La Puebla del Río (provincia de Sevilla). Sevilla: Delegación Provincial de Sevilla. Consejería de Cultura, Junta de Andalucía, 1993. Tomo II, Informe de Actividad Arqueológica. 
podría resultar beneficioso de cara a nuevos estudios sobre el mundo rural andalusí, pues podría permitir a los investigadores del territorio ir haciendo bases de datos más completas sobre las que ir trabajando, pudiendo entrar luego en el debate sobre qué categoría dar a cada tipo de yacimiento sobre la base de una realidad arqueológica mejor conocida. En los últimos años se ha apoderado de la Arqueología cierto temor al dato, pero lo cierto es que sin información de calidad difícilmente podemos ir avanzando en el conocimiento de las sociedades y culturas que nos antecedieron, y ello impide en múltiples ocasiones siquiera plantear hipótesis serias sobre las que trabajar. Esta obviedad ha sido recordada recientemente por A. García Sanjuán a la hora de analizar una serie de deficiencias en la investigación arqueológica del Medievo onubense ${ }^{48}$. No se trata de caer en la dinámica positivista de entender la ciencia como una mera descripción de lo que tenemos ante nuestros ojos, del dato por el dato, sino de montar y estructurar las propuestas sobre la base de una información rica y de calidad $^{49}$. Entendemos que es esta vía la que nos puede permitir avanzar en el conocimiento del mundo rural de Al-Andalus.

A. Malpica comentaba hace años que los datos disponibles sobre los maŷāšir, entidad que entraría por definición dentro de nuestro grupo descriptivo de asentamientos rurales secundarios, eran bastante escasos ${ }^{50}$. Si bien es cierto que en nuestra búsqueda bibliográfica no hemos consultado gran parte de la literatura disponible, lo cual no era nuestro objetivo ni respondía a nuestras aspiraciones, también lo es el hecho de que en las obras vistas, y generalmente citadas entre los especialistas en la materia, no hemos encontrado referencias a ningún sitio arqueológico que haya sido incluido dentro de esta categoría, lo cual nos hace pensar que no deben conocerse muchos más de los que se conocían cuando Malpica escribió su artículo. Ello nos ha impedido poder centrar un mínimo esfuerzo por intentar desmenuzar descriptivamente la naturaleza de los mismos, si es que los datos lo hubieran permitido y no estuviésemos ante nuevos casos de

\footnotetext{
${ }^{48}$ Vid nota 12, p. 8 .

49 En la literatura arqueológica encontramos igualmente casos en los que se hacen descripciones arqueográficas sobre yacimientos estudiados $\mathrm{y}$, pese a la pobreza documental de los materiales analizados, se comete el atrevimiento de asignar, de forma concluyente, la categoría poblacional de qarya. Para el caso andaluz esta falta de rigurosidad metodológica ha sido denunciada por GARCÍA SANJUÁN, A. - "La reciente investigación arqueológica sobre el territorio onubense durante el periodo andalusí: una revisión crítica". Arqueología y Territorio Medieval. No 13.3 (2006), pp. 21-22.

${ }^{50}$ Vid nota 17 , p. 152.
} 
etiquetas casi vacías de contenido. Podemos suponer que debieron de tratarse de entidades de poblamiento menores y que, según el caso, podrían quedar vinculadas directamente a asentamientos rurales de primer orden o a otro tipo de núcleos (madina, hisn, etc.). Estas especies de cortijadas o maŷāšir destacarían sobre todo por el hecho de tratarse de núcleos funcionalmente volcados a la explotación directa del campo ${ }^{51}$, de ahí que el contingente demográfico fuese menor, tal y como ya dijimos arriba, y por ello inferior la desproporción entre los conjuntos de cerámica de mesa-cocina y la de almacenaje. También podrían llegar a localizarse elementos o estructuras asociados a algún tipo de actividad de almacenaje o de transformación de materias primas. Esto mismo parece haberse documentado en el yacimiento aljarafeño de la Dehesa de Puñana (La Puebla del Río, Sevilla), donde se han localizado un silo, varios estanques y piedras de molino, quizás asociados a actividades oleicultoras ${ }^{52}$, aunque la adscripción cronológica no queda clara ni tampoco podemos saber si el yacimiento debe interpretarse como un asentamiento rural de primer o segundo orden. A nivel general, este tipo de enclaves rurales no debieron contar con mezquitas aljamas. Para la oración del viernes (Salāt al-Ŷum 'a) sus pobladores debieron ir, en función de la cercanía, a aquéllas situadas en los de primer orden, en los ḥusūn o en las ciudades, tal y como se contempla en las colecciones de dictámenes jurídicos o fetuas ${ }^{53}$. Aunque no debe descartarse la posibilidad de la existencia de algún pequeño oratorio destinado a la realización de las cinco oraciones diarias.

Siguiendo con los asentamientos rurales de segundo orden deben citarse los rahâal. Tal y como comentan M. Barceló y J. Pascual ${ }^{54}$, algunos investigadores han entendido que la palabra raḥl hace referencia a una especie de hacienda agrícola privada y extraurbana de

\footnotetext{
${ }^{51}$ Cf. OLIVER, J. - "May̌šar - Cortijo. Orígenes y nomenclatura árabe del cortijo sevillano". Al-Andalus. No 10, Vol. 1 (1945), pp. 109-126.

52 SALAS, J. de la A. y MESA, M. - "Prospección arqueológica superficial del término municipal de La Puebla del Río (provincia de Sevilla)". Anuario Arqueológico de Andalucía 1993. Vol. III (1997), p. 795; y SALAS, J. de la A. y MESA, M. - "La Dehesa de Puñana: una alquería almohade en el sur del Aljarafe sevillano”. Boletín Asociación Española de Amigos de la Arqueología. No 41 (2001), pp. 132 y 135.

${ }^{53}$ CALVO, S. - "Las mezquitas de pequeñas ciudades y núcleos rurales de al-Andalus". 'Ilu. Revista de Ciencias de las Religiones. Anejos. N 10 (2004), p. 42.

${ }^{54}$ BARCELÓ, M. - "Vísperas de feudales. La sociedad de Sharq al-Andalus justo antes de la conquista catalana". In MAÍLLO, F. - España, Al-Andalus, Sefarad: síntesis y nuevas perspectivas. Salamanca: Universidad de Salamanca, 1988, p. 103; y PASCUAL, J. - "Etimología y origen del topónimo Arahal”. Al-Andalus-Magreb: Estudios árabes e islámicos. No 5 (1997), pp. 261-262.
} 
carácter aristocrático $^{55}$. Si bien es cierto que se trata de una acepción posible, aunque el término adecuado para designarla debería ser riya $\bar{d}^{56}$, por regla general dicho significado se cumple cuando la palabra va seguida de un nombre propio específico (por ejemplo rahal del Longo, rahal Azappatayr o rahal Palumber), tal y como se documenta con frecuencia en el Levante peninsular, no tratándose del significado genérico lingüístico ${ }^{57}$. Llaman igualmente la atención algunos rahāal que a nivel toponímico vienen acompañados de prefijos o partículas clánicas como banu o beni ${ }^{58} \mathrm{y}$ que quizás no debieron aludir a particulares, sino a colectivos gentilicios. El término raḥl también puede traducirse como granja, e incluso como cobijo de pastores ${ }^{59}$. La granja (raḥl) se vuelca funcionalmente sobre todo hacia la explotación pecuaria-pastoril; en cambio, el cortijo (maŷšar) se vuelca más hacia la explotación agraria. Sin embargo, si aceptásemos estas últimas acepciones, arqueológicamente resultaría complicado discernir en superficie una realidad de la otra, de ahí que las equiparemos a nivel de tecnicismo de cara a actividades prospectivas. Un ejemplo de raḥl podría encontrarse documentado en el Alto de la Mezquita (Senés, Almería) ${ }^{60}$.

El propio P. Cressier ya puso de manifiesto una situación ante la cual debemos prestar un mínimo de atención y de reflexión. Cressier sostenía que a veces nos encontramos ante «un grupo de núcleos de hábitat [que] a veces demasiado rápidamente [son] asimilados a qura [cuando] no son en realidad más que barrios (hara) de un mismo conjunto ${ }^{61}$. Los asentamientos rurales pueden definirse a través de entidades

${ }^{55}$ Por ejemplo GUICHARD, P. - "El problema de la existencia de estructuras de tipo feudal en la sociedad de Al-Andalus. El ejemplo de la región valenciana". In BONNASSIE, P. et al. - Estructuras feudales y feudalismo en el mundo mediterráneo (siglos X-XIII). Barcelona: Ed. Crítica, 1984, pp. 117145; y GUICHARD, P. - Al-Andalus frente a la conquista cristiana. Los musulmanes de Valencia (siglos XI-XIII). Madrid-Valencia: Ed. Biblioteca Nueva-Universitat de València, 2001.

${ }^{56}$ RUBIERA, M. J. - "Rafals y raales; ravals y arrabales; reals y reales". Sharq Al-Andalus. No 1 (1984), pp. 120-121.

57 PASCUAL, J. - "Etimología y origen del topónimo Arahal”. Al-Andalus-Magreb: Estudios árabes e islámicos. No 5 (1997), pp. 261-262.

${ }_{58}$ POVEDA, A. R. - "Introducción al estudio de la toponimia árabe-musulmana de Mayurqa según la documentación de los archivos de la Ciutat de Mallorca". Awraq. No 3 (1980), pp. 80, 84-85, 90-91 y 9495.

${ }^{59}$ Vid nota 57, pp. 261 y 263-266.

${ }^{60}$ CRESSIER, P. y DELAIGUE, M.-C. - "Poblamiento y cultura material en un territorio elemental medieval de la Sierra de los Filabres. El valle de Senés (Almería). Campaña 1990”. Anuario Arqueológico de Andalucía 1990. Vol. II. (1992), p. 197.

${ }^{61}$ CRESSIER, P. - "Agua, fortificaciones y poblamiento. El aporte de la arqueología a los estudios sobre el Sureste peninsular”. Aragón en la Edad Media. No 9 (1991), p. 412. En la cita, las palabras entre corchetes son nuestras. 
poblacionales nucleadas, sin embargo, tal y como ha puesto de manifiesto M. Barceló, ello no debe asumirse de forma axiomática ya que se pueden dar diversas variantes, tanto en los espacios domésticos como en los espacios de trabajo, que permitan esgrimir la idea de una entidad poblacional de partes dispersas ${ }^{62}$. La realidad de asentamientos rurales de planta dispersa debería obligar al investigador a contemplar en sus estudios las posibles relaciones espaciales entre los yacimientos con el fin de poder establecer una jerarquización de los mismos. Quizás aquí tendríamos que abordar cuestiones relativas a estudios de etnicidad a través de la cultura material. Pongamos por ejemplo el caso de la mezquita rural de Velefique (Almería) ${ }^{63}$. A ella acudían creyentes de distintos núcleos que bien podrían pertenecer a entidades gentilicias distintas (o bien no), pero que se unían en un lugar religioso como miembros de la umma para cumplir con sus obligaciones como fieles. Por tanto, ¿cómo podemos discernir la relación de los lugares? ¿Se trataba de sitios distintos pertenecientes a una misma comunidad o de asentamientos diversos de comunidades diferentes? Entendemos que el análisis de los sistemas hidráulicos de irrigación puede ser una buena vía para intentar hacer frente a este tipo de cuestiones, pues podría permitir ver cómo se articula un conjunto de lugares respecto a una red de abastecimiento de agua y la forma en que lo hacen. A. Malpica nos dice que «la importancia del sistema de regadío radica en la gestión social del mismo. El establecimiento de las áreas irrigadas está calculado para un grupo humano que sea capaz de organizarlo y mantenerlo» ${ }^{64}$. A través de la morfología y la evolución de tales sistemas puede incidirse en aspectos relativos a dicha gestión, y aproximarnos a los tipos de comunidades campesinas que intervinieron en su construcción y las relaciones existentes entre ellas. Ejemplos de este tipo de estudio han sido realizados en entornos mallorquines como los de Coanegra, Bunyola, Alaró o Castellitx, así como en los ibicencos de Buscatell y Xarraca ${ }^{65}$. También es interesante tener en cuenta si un mismo asentamiento, caso de Alcariais de Odeleite ${ }^{66}$, se encuentra seccionado por algún tipo de item paisajístico, como por ejemplo desniveles topográficos, un arroyo, una

\footnotetext{
${ }^{62}$ Vid nota 16, p. 106.

${ }^{63}$ GLICK, T. F. - Paisajes de conquista. Cambio cultural y geográfico en la España medieval. Valencia: Universitat de València, 2007, pp. 44-45.

${ }^{64}$ Vid nota 18, p. 201.

${ }^{65}$ Vid nota 42, pp. 139-161.

${ }^{66}$ Vid nota 32, pp. 571-572 y 585.
} 
vaguada, un camino, etc., para tratar de explicar las relaciones entre las partes, y entre éstas y el elemento separador.

\section{Definición historiográfica del concepto qarya}

Se habrá podido observar cierta cautela o negativa a la hora de emplear la palabra alqurà en las anteriores líneas, pues pensamos que, lejos de las magníficas descripciones que de éstas pueden darse sobre la base de las fuentes escritas o desde posiciones que las caracterizan ciñéndose a aspectos relativos a los sistemas de propiedad o a las formas sociales que en ellas habitaban, el abuso de este término perjudica más que ayuda a la hora de conocer arqueológicamente el territorio andalusí. Cuando un arqueólogo está en el campo se encuentra ante conglomerados de cultura material, y es éste el primer problema que debe resolver antes de dar el siguiente paso. No podemos empezar la casa por el tejado. Sin embargo, y estas líneas van dedicadas a aquellos que quieran tener una idea de lo que por lo general suele decirse de estos tipos de asentamientos rurales $^{67}$, vamos a realizar una síntesis de lo que por ellas suele entenderse en la literatura especializada.

Grosso modo tiende a considerarse que la comunidad que vivía en estos tipos de unidades de poblamiento se caracterizaría por quedar sus miembros unidos por fuertes lazos de parentesco, al tratarse de clanes compuestos por familias unidas por consanguinidad, de ahí que nos encontremos con la existencia de topónimos de origen árabe que hagan referencia a algún gentilicio ${ }^{68}$. Aún así, la cohesión a través de relaciones de parentesco «no implica ninguna rigidez étnica excepto en su aspecto más formalizado -de hecho el clan acepta inmigrantes ajenos-» ${ }^{69}$. La dinámica de la comunidad se vincula sobre todo a la explotación del medio rural circundante, el cual gestiona de cara a la obtención de recursos agropecuarios. En la organización del

\footnotetext{
${ }^{67}$ Hablamos de «tipos de asentamientos», en plural, incidiendo una vez más en el carácter polisémico que dicha palabra tiene en el idioma árabe.

${ }^{68}$ Cf. DOMÍNGUEZ, E. L. - "El registro territorial de Alcalá de Guadaira en época norteafricana (ss. XIXIII)". Actas de las VI Jornadas de Historia de Alcalá de Guadaira. Alcalá de Guadaira: Ayuntamiento de Alcalá de Guadaira, 2000, p. 13.

${ }^{69}$ Vid nota 16, p. 107.
} 
proceso de trabajo las distintas casas debieron de estar coordinadas, pudiendo jugar el consejo de ancianos (shuyūkh) un papel relevante $\mathrm{e}^{70}$.

El territorio de estas comunidades se dividía en varias $\operatorname{partes}^{71}$ : A) propiedades privadas de grupos parentales o mamlūka, por lo general inclinadas al cultivo de regadío y ocasionalmente de secano; B) tierra comunal o harim, destinado para su uso como pastizal, caza, obtención de madera, recolección de frutos silvestres, etc.; y C) tierras muertas o mawāt, que consistían en una serie de espacios incultos pertenecientes a la comunidad que, debido a su carácter distante respecto al núcleo, podían ser puestas en cultivo (probablemente de secano) por cualquier miembro del grupo para sacar cierto rendimiento $^{72}$. T. F. Glick comenta que «el tamaño de los territorios de las alquerías [...] se sitúa entre 72 y 90 ha, según las dimensiones efectuadas por los colonizadores cristianos, dado que las alquerías andalusíes carecían, en principio, de límites fijos ${ }^{73}$. A nosotros nos cuesta trabajo creer que una sociedad que invirtió tanta energía en la mantención de importantes sistemas hidráulicos de irrigación no tuviera unos límites más o menos claros y definidos sobre el territorio de la comunidad, hecho que el mismo investigador llega a reconocer líneas más abajo. Estos límites no tienen por qué fundamentarse en una rigurosa estructuración lineal del espacio, sino que podrían haber pivotado sobre la base de ítems paisajísticos, tales como riachuelos, cerros, montañas, caminos, arboledas, etc. También sostiene este autor que la mayoría de las qurà eran pequeñas, lo que podría definirse bajo el término de caserío, es decir, una reunión de varias casas asociadas a tierras de labor ${ }^{74}$. Esto nos llevaría de nuevo a poner sobre la mesa la ambigüedad que el término tiene en el propio idioma árabe, pues si bien T. F. Glick tiene en parte razón, existen qurà de mayor tamaño y volumen poblacional ${ }^{75}$.

\footnotetext{
${ }^{70}$ Idem, pp. 107-108.

71 TRILLO, C. - "La alquería y su territorio en Al-Andalus: estrategias sociales de organización y conservación”. Arqueología Espacial. No 26 (2006), pp. 243-262.

72 GUICHARD, P. - Al-Andalus frente a la conquista cristiana. Los musulmanes de Valencia (siglos XIXIII). Madrid-Valencia: Ed. Biblioteca Nueva-Universitat de València, 2001, pp. 308-309 añade, por otra parte, que las qurà se caracterizaban por la explotación comunal de la tierra, mientras que las diy $\bar{a}$ ' (sg. day 'a) serían propiedades o «dominios privados».

${ }_{73}$ Vid nota 63 , p. 41.

${ }^{74}$ Idem, p. 42.

${ }^{75}$ Vid nota 18, p. 204.
} 
Tales asentamientos constituían igualmente unidades de captación fiscal dentro del Estado islámico ${ }^{76}$. La parte restante del excedente de producción era retenida dentro de la comunidad y distribuida desigualmente en función del lugar que las casas ocupaban dentro de la jerarquía social comunitaria ${ }^{77}$.

Las qurà debieron contar igualmente con pequeñas mezquitas, elemento fundamental en la vida cotidiana de las comunidades islámicas. A. García Sanjuán llama la atención sobre el hecho relativo a la documentación de mezquitas, insistiendo que su presencia no resulta un factor determinante para proclamar el carácter urbano de un asentamiento, ya que las comunidades rurales podían igualmente disponer de ellas ${ }^{78}$. Algunos casos de los que se tiene constancia material pueden ser, por ejemplo, los de la mezquita del Cortijo del Centeno (Lorca, Murcia), la de Nigüelas (Valle de Lecrín, Granada) y la de Xara (Simat de la Valldigna, Valencia) ${ }^{79}$. A través de los textos sabemos igualmente de su existencia en Leuxa o Mondújar (Valle de Lecrín, Granada) ${ }^{80}$. Estos edificios religiosos no sólo se destinaban al culto, sino que también pudieron funcionar como escuelas (madrasa / madāris), así como lugar de reuniones y de debates, etc. Parte fundamental de la vida comunitaria se desarrollaba en torno a ellas o en ellas ${ }^{81}$. Dado el caso, los minaretes anexos a las mismas pudieron llegar a funcionar como torres

\footnotetext{
${ }^{76}$ GUICHARD, P. - "Le probleme des structures agraries en Al-Andalus avant la conquete chretienne". In CABRERA, E. - Andalucía entre Oriente y Occidente (1236-1492). Actas del V Coloquio Internacional de Historia Medieval de Andalucía. Córdoba: Diputación Provincial, 1988, pp. 163 y 169; y MARTÍNEZ, A. - "La alquería, unidad de poblamiento básica en el al-Andalus rural". Boletín de la Asociación Provincial de Museos Locales de Córdoba. Nº 6 (2005), pp. 115-116.

${ }_{77}^{77}$ Vid nota 16, pp. 107-108.

${ }^{78}$ Vid nota 12, p. 15.

${ }^{79}$ AZUAR, R. - "Las mezquitas en el ámbito rural". In - Actas de las II Jornadas de Cultura Árabe e Islámica (1980). Madrid: Instituto Hispano-Árabe de Cultura, 1985, pp. 65-72; AZUAR, R. "Arqueología medieval del País Valenciano y Murcia". In - Arqueología del País Valenciano: panorama y perspectivas. Alicante: Universidad de Alicante, 1985, pp. 415-446; ESPINAR, M. y PADILLA, L. "Nigüelas, una alquería musulmana del Valle de Lecrín: la mezquita y otros centros religiosos". In ESPINAR, M. y GARCÍA, M. M. - La ciudad medieval y su territorio. I: Urbanismo, sociedad y economía. Cádiz: Agrija Ediciones, 2009, pp. 71-94; y PUJANTE, A. - "La mezquita rural de la alquería del Cortijo del Centeno. Lorca, Murcia". Revista de Arqueología. Año 21, No 234 (2000), pp. 42-49.

${ }^{80}$ ESPINAR, M. - "La alquería de Mondújar: mezquita y rábitas, cementerios, barrios y otras estructuras urbanas y rurales". Anaquel de Estudios Árabes. No 11 (2000), pp. 277-294; y ESPINAR, M. - "Noticias sobre la alquería de Leuxa, Aleuxa o Lojuela. Un despoblado medieval del Valle de Lecrín". In ESPINAR, M. y GARCÍA, M. M. - La ciudad medieval y su territorio. I: Urbanismo, sociedad y economía. Cádiz: Agrija Ediciones, 2009, pp. 49-70.

${ }^{81}$ ESPINAR, M. y PADILLA, L. - "Nigüelas, una alquería musulmana del Valle de Lecrín: la mezquita y otros centros religiosos". In ESPINAR, M. y GARCÍA, M. M. - La ciudad medieval y su territorio. I: Urbanismo, sociedad y economía. Cádiz: Agrija Ediciones, 2009, p. 73.
} 
defensivas y de vigilancia ante casos de peligro ${ }^{82}$. Igualmente, se tiene constancia de casos donde un asentamiento rural disponía de una mezquita aljama a la que acudían pobladores de lugares cercanos para la realización de la oración del viernes, caso del yacimiento de Velefique en Almería ${ }^{83}$. De ser ello así, la mezquita rural no sólo debe entenderse como un elemento fundamental para la comprensión de la comunidad que habita la qarya en la que se emplaza, sino también como clave estructural de un territorio algo más amplio.

\section{Conclusiones}

Creemos haber puesto de manifiesto la existencia de un fenómeno de disfunción etimológica entre la palabra castellana alquería y el término árabe qarya. El primer concepto suele hacer referencia a cortijadas desde las que se explota el entorno rural, y es este sentido el que muchos arqueólogos, sobre todo de Andalucía occidental, han aplicado a la hora de aproximarse al mundo rural de Al-Andalus. Sin embargo, en la literatura especializada la definición dada suele corresponderse con la que hemos esgrimido en el anterior apartado, aproximándose a uno de los sentidos semánticos que en árabe contiene la palabra qarya. No obstante, la riqueza semántica de dicho idioma a menudo suele menospreciarse, y muchos historiadores y arqueólogos no han contemplado las otras acepciones que el término encierra y que arroja ambigüedad de cara a su uso en la caracterización arqueológica del poblamiento andalusí. Ante tal tarea, la de caracterizar el mundo rural de Al-Andalus, se ha intentado expresar la necesidad de comenzar a trabajar sobre la base de una estrategia descriptiva que permita obtener datos arqueológicos con la calidad suficiente como para que, en una segunda fase, se trate de esclarecer qué tipo de asentamientos son los estudiados. Ante ello, se ha realizado una propuesta metodológica, a nuestro parecer abierta y flexible, orientada a dicha tarea descriptiva a partir del análisis de una serie de variables que se han ido discutiendo a lo largo del trabajo.

\footnotetext{
${ }^{82}$ Vid nota 53, pp. 48-49.

${ }^{83}$ Vid nota 63, pp. 44-45.
} 
Data recepção do artigo: 21 de Fevereiro de 2013

Data aceitação do artigo: 3 de Junho de 2013

\section{COMO CITAR ESTE ARTIGO}

\section{Referência electrónica:}

PÉREZ AGUILAR, Luis Gethsemaní - "Problemas metodológicos en el estudio del mundo rural andalusí”. Medievalista [Em linha]. №14, (Julho - Dezembro 2013). [Consultado dd.mm.aaaa]. Disponível em http://www2.fcsh.unl.pt/iem/medievalista/MEDIEVALISTA14/aguilar1406.html. ISSN 1646-740X.

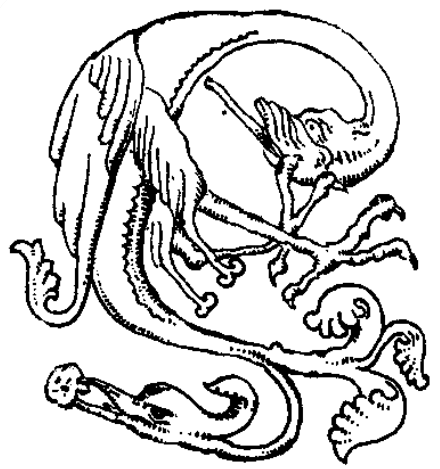


FIGURA 1: Datos referentes a diversos yacimientos rurales andalusíes.

\begin{tabular}{|c|c|c|c|c|c|c|c|c|}
\hline NOMBRE & $\begin{array}{c}\text { TEC.DE } \\
\text { DOCUMENTACIONN }\end{array}$ & EXTENSIOON & EMPLAZAMIENTO & $\begin{array}{l}\text { TIPOS DE MAT. } \\
\text { CONSTRUCTIVO }\end{array}$ & FORMAS CERAMICAS & $\begin{array}{l}\text { DENSIDAD DE LOS } \\
\text { TIPOS CERAMMICOS }\end{array}$ & OTROS & BIBUOGRAFIA \\
\hline $\begin{array}{l}\text { Alcariais de } \\
\text { Odeleite (Castro } \\
\text { Marim, Faro) }\end{array}$ & $\begin{array}{l}\mathrm{P} \\
\mathrm{E}\end{array}$ & $\begin{array}{l}\text { E? hat } \\
0,1683 \text { ha } \\
\text { excavadas }\end{array}$ & $\begin{array}{l}1 \\
3 \\
4\end{array}$ & $\begin{array}{l}\text { Piedra, Brava, lajas } \\
\text { de esquisto, barro, } \\
\text { argamasa de cal y } \\
\text { arena, tejas, } \\
\text { material reutilizado } \\
\text { (tégulas, ladrillos, } \\
\text { sillares, cornisa, } \\
\text { monolito) }\end{array}$ & $\begin{array}{l}\text { Redomas, jarros, ollas, } \\
\text { cazuelas, tapaderas, } \\
\text { ataifores, lebrillos, } \\
\text { cantaros, candiles, tinajas } \\
\text { de almacenamiento, } \\
\text { tablero de juego y fichas, } \\
\text { pesas de telar, pila de } \\
\text { abluciones }\end{array}$ & $\begin{array}{l}\text { Alta presencia de } \\
\text { cerámica de cocina y } \\
\text { de mesa }\end{array}$ & $\begin{array}{l}\text { Estructuras domésticas, establos } \\
\text { o corrales, almacenes, zonas de } \\
\text { huertas, horno, hogares, } \\
\text { braseros, martillo de hierro, } \\
\text { fragmentos de pledras de } \\
\text { molino, monedas, llave, arado, } \\
\text { plato de balanza, fragmentos de } \\
\text { vidrio, huesos de animales }\end{array}$ & $\begin{array}{c}\text { Catarino, 1997-98 } \\
\text { Carvalho dos Santos, } 2008 \\
\text { Pereira, } 2012\end{array}$ \\
\hline $\begin{array}{l}\text { Alcaria Longa } \\
\text { (Mértola, Beja) }\end{array}$ & $\begin{array}{l}\text { "p" } \\
\mathrm{E}\end{array}$ & $" 4 \circ 5^{\prime \prime h a}$ & $\begin{array}{l}1 \\
3 \\
4\end{array}$ & $\begin{array}{l}\text { Piedra, tejas, grava, } \\
\text { losas, lajas de } \\
\text { esquisto, ladrillos, } \\
\text { tapial }\end{array}$ & $\begin{array}{l}\text { Ollas, ataifores, candiles, } \\
\text { jarras, jarros, jarritas, } \\
\text { cazuełas, lebrillos, } \\
\text { redomas }\end{array}$ & 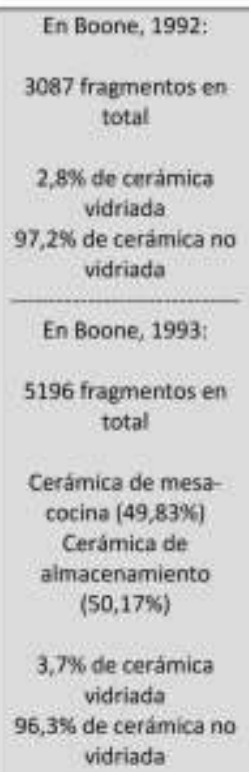 & $\begin{array}{l}\text { Estructuras domésticas, de } \\
\text { manufactura (foria) y defensivas } \\
\text { (torrel, hogares, chimenea, } \\
\text { huesos de animales, conchas de } \\
\text { moluscos marinos, anillos, } \\
\text { monedas de plata, fragmentos de } \\
\text { vidrio, tachuelas y clavos de } \\
\text { puertas, fragementos de hierro } \\
\text { indefinidos, husos de bronce, } \\
\text { rueca de hueso de catra, } \\
\text { botones, escoria de metal, daga } \\
\text { con empunadura de bronce } \\
\text { decorada, pequeños eslabones } \\
\text { de plata, martillo de hierro, } \\
\text { herradura, cuenta de piedra }\end{array}$ & $\begin{array}{l}\text { Boone, } 1992 \\
\text { Boone, } 1993\end{array}$ \\
\hline
\end{tabular}




\begin{tabular}{|c|c|c|c|c|c|c|c|c|}
\hline $\begin{array}{l}\text { La Dehesa de } \\
\text { Puñana I y II } \\
\text { (La Puebla del fio, } \\
\text { Sevilla) }\end{array}$ & $P$ & $227,2 ? \mathrm{ha} \mathrm{a}^{\circ}$ & $\begin{array}{l}1 \\
3 \\
4\end{array}$ & $\begin{array}{l}\text { Piedra, ladrilios, } \\
\text { sillares, tégulas, } \\
\text { imbrices, tejas }\end{array}$ & $\begin{array}{l}\text { Cuencos, attaifores, } \\
\text { lebrillos, marmitas, ollas, } \\
\text { jarritos/as, anafes, } \\
\text { cazuelas, tinajas, } \\
\text { arcaduces, tapadera }\end{array}$ & "Abundante" & $\begin{array}{l}\text { Estanques \{2aimazara?), piedras } \\
\text { de molino, poro, silo }\end{array}$ & $\begin{array}{l}\text { Salas y Mesa, 1993, T.II y IV } \\
\text { Salas y Mesa, } 1997 \\
\text { Salas y Mesa, } 2001\end{array}$ \\
\hline $\begin{array}{l}\text { Los Olivos } \\
\text { (La Puebla del Rio, } \\
\text { Sevilla) }\end{array}$ & P & $4,3 \mathrm{ha}$ & $\begin{array}{l}1 \\
3 \\
4\end{array}$ & $\begin{array}{l}\text { Tejas, piedra, } \\
\text { tégulas }\end{array}$ & $\begin{array}{l}\text { Lebrillos, ollas, ataifores, } \\
\text { tinajas, atros, tapadera. }\end{array}$ & "Abundante" & Pozo & $\begin{array}{l}\text { Salas y Mesa, 1993, T-11i y IV } \\
\text { Salas y Mesa, } 1997\end{array}$ \\
\hline $\begin{array}{c}\text { El Cruce } \\
\text { (La Puebla del Rio, } \\
\text { Sevilla) }\end{array}$ & $\mathrm{P}$ & $1,2 \mathrm{ha}$ & $\begin{array}{l}1 \\
3 \\
4\end{array}$ & $\begin{array}{l}\text { Piedra, tejas, } \\
\text { tégulas, imbrices }\end{array}$ & Botella, cazuelas & ¿? & Pozo & $\begin{array}{l}\text { Salas y Mesa, 1993, T.ll y IV } \\
\text { Salas y Mesa, } 1997\end{array}$ \\
\hline $\begin{array}{l}\text { Los Eucaliptos (La } \\
\text { Puebla del Rio, } \\
\text { Sevilla) }\end{array}$ & P & 1,4 ha & $\begin{array}{l}1 \\
3 \\
4\end{array}$ & $\begin{array}{l}\text { Tejas, piedra, } \\
\text { tégulas, ladrillos }\end{array}$ & $\begin{array}{l}\text { Cuencos, platos, tapadera, } \\
\text { redomas } / \text { jarras, cazuelas, } \\
\text { ataifores, alcadafes, } \\
\text { lebrillos }\end{array}$ & "Abundante" & Pozo & $\begin{array}{l}\text { Salas y Mesa, 1993, T.JI y IV } \\
\text { Solas y Mesa, 1997 }\end{array}$ \\
\hline $\begin{array}{l}\text { Olivar del Molino } \\
\text { (Castellar de la } \\
\text { Frontera, Cádiz) }\end{array}$ & $\mathrm{p}$ & $10 \mathrm{ha}$ & $\begin{array}{l}1 \\
2 \\
3 \\
4\end{array}$ & $\begin{array}{l}\text { Piedra, ladrillos, tejas, } \\
\text { sillares, tégulas }\end{array}$ & $\begin{array}{c}\text { Cazuelas, marmitas, ataifores, } \\
\text { jarritos/as, jofainas; } \\
\text { tapaderas, orzas, jarros/as, } \\
\text { tinajas, alcadafes }\end{array}$ & ¿? & $\begin{array}{l}\text { Restos de muros, estructuras } \\
\text { hidraulicas (pozo, canal y pilón con } \\
\text { posible noria), restos de muro } \\
\text { defensivo o torreón. }\end{array}$ & Sevilla et oli, 2003 \\
\hline $\begin{array}{l}\text { Los Parrales } \\
\text { (San Juan del } \\
\text { Puerto, Huelva) }\end{array}$ & $E$ & e? & ¿? & $\begin{array}{l}\text { Ladrillos, "material } \\
\text { tomano reutilizado" }\end{array}$ & Marmita, jarrito, jarrita & 27 & $\begin{array}{l}\text { Resto de muro de estructura de } \\
\text { almacenamiento (mortero } \\
\text { hidraulico), basurero }\end{array}$ & Pérez, 2003 \\
\hline $\begin{array}{c}\text { Purchena / Los } \\
\text { Cascos } \\
\text { (Chucena, Huelva) }\end{array}$ & P & 2,5 ha & $\begin{array}{l}1 \\
4 \\
5\end{array}$ & $2 ?$ & $\begin{array}{l}\text { Ataifores, jarritas, } \\
\text { marmitas, cazuelas, } \\
\text { tinajas, orzas, alcadafes }\end{array}$ & "Abundante" & L? & Pérez y Serrano, 2004 \\
\hline $\begin{array}{l}\text { Matillas } \\
\text { (Castellar de la } \\
\text { Frontera, Cádiz) }\end{array}$ & $P$ & $\begin{array}{c}\text { ¿? ha } \\
\text { "Pequeño } \\
\text { asentamiento } \\
\text { rural" }\end{array}$ & $\begin{array}{l}1 \\
2 \\
3\end{array}$ & ¿? & $\begin{array}{l}\text { Cazuelas, marmitas, } \\
\text { ataifores, jarritos/as, } \\
\text { jofainas, tapaderas, orzas, } \\
\text { jarros/as, tinajas, akcadafes }\end{array}$ & $c^{7}$ & $\begin{array}{c}\text { ¿Mismo asentamiento que el } \\
\text { yacimiento de Olvar del Molino, } \\
\text { pero al otro lado un arroyo?, } \\
\text { derrumbes }\end{array}$ & Sevilla et alli, 2003 \\
\hline $\begin{array}{l}\text { Loma de Hato } \\
\text { Alto } \\
\text { [Castellar de ba } \\
\text { Frontera, Cádiz) }\end{array}$ & $\mathrm{P}$ & $\begin{array}{c}\text { ¿?ha } \\
\text { "Pequeño } \\
\text { asentamiento } \\
\text { rurat" }\end{array}$ & $\begin{array}{l}1 \\
2 \\
3\end{array}$ & ¿? & c? & ¿? & $\begin{array}{l}\text { ¿Mismo asentamiento que el } \\
\text { yacimiento de Olivar del Molino? }\end{array}$ & Sevilla et alii, 2003 \\
\hline $\begin{array}{l}\text { Corrijo Garranchal } \\
\text { iCastellar de la }\end{array}$ & P & $\begin{array}{l}\text { C?ha } \\
\text { aran }\end{array}$ & $\begin{array}{l}1 \\
3\end{array}$ & $\begin{array}{l}\text { "Material } \\
\text { constructivo". }\end{array}$ & Ataifores, otras (2?) & ¿? & Restos de muros $y$ de derrumbes & Sevilla et all, 2003 \\
\hline
\end{tabular}

Las ha de este yacimiento han sido calculadas por nosotros tras introducir las coordenadas UTM proporcionadas por sus prospectores en un SIG. La excesiva extensión del sitio nos llevó a poner en cuarentena tal dato. Los propios prospectores han tenido la amabilidad de comunicarnos personalmente que, a pesar de tratarse de un asentamiento grande, existe la posibilidad de haberse cometido algún error en la toma de las coordenadas. 


\begin{tabular}{|c|c|c|c|c|c|c|c|c|}
\hline Frontera, Cádiz) & & $\begin{array}{l}\text { asentamiento } \\
\text { rurar" }\end{array}$ & 4 & tégulas, sillares & & & & \\
\hline $\begin{array}{l}\text { Cortijo Barría } \\
\text { (Castellar de Ia } \\
\text { Frontera, Cadiz) }\end{array}$ & $P$ & $\begin{array}{l}\text { ¿? ha } \\
\text { "Gran } \\
\text { asentamiento } \\
\text { rural" }\end{array}$ & $\begin{array}{l}1 \\
3 \\
4\end{array}$ & 27 & ¿? & ¿? & Restos de muros y de derrumbes & Sevilla et alik, 2003 \\
\hline $\begin{array}{c}\text { Corral de las } \\
\text { Vacas } \\
\text { (Castellar de la } \\
\text { frontera, Cadiz) }\end{array}$ & P & $\begin{array}{l}\text { ¿? ha } \\
\text { "Gran } \\
\text { asentamiento } \\
\text { rural" }\end{array}$ & $\begin{array}{l}1 \\
3 \\
4\end{array}$ & Tejas, ladrillos & ह? & $e^{2}$ & d? & Sevilla et all, 2003 \\
\hline $\begin{array}{l}\text { El Chorrito } \\
\text { (Castellar de la } \\
\text { Frontera, Cádiz) }\end{array}$ & $\mathrm{p}$ & $\begin{array}{l}\text { ¿? ha } \\
\text { "Gran } \\
\text { asentamiento } \\
\text { rurar" }\end{array}$ & $\begin{array}{l}1 \\
3 \\
4\end{array}$ & ¿? & $t^{2}$ ? & ¿? & $\begin{array}{l}\text { Restos de muros, evidencia de } \\
\text { calles }\end{array}$ & Sevilla et alli, 2003 \\
\hline $\begin{array}{l}\text { Dehesa de Cotilla } \\
\text { (Castellar de la } \\
\text { Frontera Cádiz) }\end{array}$ & $P$ & $\begin{array}{c}\text { ¿? ha } \\
\text { Pequeño } \\
\text { asentamiento } \\
\text { rurar }\end{array}$ & $\begin{array}{l}1 \\
3 \\
4\end{array}$ & ¿? & E? & ¿? & ¿? & Sevilla et alin, 2003 \\
\hline $\begin{array}{l}\text { El Ermitaño } \\
\text { (Castellar de la } \\
\text { Frontera, Cádiz) }\end{array}$ & P & $\begin{array}{l}\text { ¿? ha } \\
\text { "Pequeño } \\
\text { asentamiento } \\
\text { rurar" }\end{array}$ & $\begin{array}{l}1 \\
3 \\
4\end{array}$ & $\begin{array}{l}\text { Tejas, ladrillos; } \\
\text { bloques de piedra. }\end{array}$ & ¿? & $\begin{array}{l}\text { "Numerosos } \\
\text { fragmentos" }\end{array}$ & $\begin{array}{l}\text { Próximo a la torre de La } \\
\text { Almoraima, derrumbes }\end{array}$ & Sevilla et ali, 2003 \\
\hline $\begin{array}{c}\text { Huerta de } \\
\text { Santa Clara } \\
\text { (Castellar de la } \\
\text { Frontera, Cádiz) }\end{array}$ & $P$ & $\begin{array}{l}\text { ¿? ha } \\
\text { "Pequeño } \\
\text { asentamiento } \\
\text { rurar" }\end{array}$ & $\begin{array}{l}1 \\
3 \\
4\end{array}$ & 27 & Candil, otras (Z7) & "Dispersos" & ¿Torreón? & Sevilla et alli, 2003 \\
\hline $\begin{array}{l}\text { La forrecilla } \\
\text { (Castellar de la } \\
\text { Frontera, Cádiz) }\end{array}$ & $p$ & $\begin{array}{c}\text { ¿? ha } \\
\text { "Pequeño } \\
\text { asentamiento } \\
\text { rural" }\end{array}$ & e? & ¿? & Jarros, cántaros, otras (i̇?\}) & $c^{?}$ & $\begin{array}{l}\text { ¿Mlismo asentamiento que el } \\
\text { yacimiento de Huerta de Santa } \\
\text { Clara?, derrumbes, ttorreón? }\end{array}$ & Sevilla et alli, 2003 \\
\hline $\begin{array}{l}\text { La Mesa } \\
\text { (Chicfana de la } \\
\text { Frontera) }\end{array}$ & $\mathrm{E}$ & $\begin{array}{c}\text { c? ha } \\
0,0442 \text { has } \\
\text { excavadas }\end{array}$ & $\begin{array}{l}1 \\
3 \\
4\end{array}$ & $\begin{array}{l}\text { Sillares, adobe, } \\
\text { piedra, tejas, } \\
\text { ladrillos }\end{array}$ & $\begin{array}{l}\text { Ataifores, redomas, tazas, } \\
\text { jarritos/as, marmitas, } \\
\text { carvelas, tapaderas, } \\
\text { candiles, anafe, alcadafes, } \\
\text { jarra/o, tinajas, orzas, } \\
\text { cantimploras, pileta de } \\
\text { abluciones }\end{array}$ & $\begin{array}{c}\text { Algo más de } 495 \\
\text { piezas identificadas } \\
\text { Cerámica de mesa- } \\
\text { cocina (72-80\%6) } \\
\text { Cerámica de } \\
\text { almacenamiento (30- } \\
8 \% \text { ) }\end{array}$ & $\begin{array}{c}\text { Torre de alqueria, silos, calles, } \\
\text { canalizaciones, restos óseos de } \\
\text { bóvidos, ovicápridos y cérvidos, } \\
\text { malacofauna, semillas, } \\
\text { basureros, escorias de metal, } \\
\text { restos de casas, metal, monedas, } \\
\text { molino }\end{array}$ & $\begin{array}{l}\text { Ramos et alii, 1999a } \\
\text { Ramos et oli, } 1999 \mathrm{~b} \\
\text { Fernández, } 2007\end{array}$ \\
\hline
\end{tabular}




\begin{tabular}{|c|c|c|c|c|c|c|c|c|}
\hline $\begin{array}{c}\text { Látigo de } \\
\text { Monteagudo III } \\
\text { (Sanlúcar de } \\
\text { Barrameda, Cádiz) }\end{array}$ & $P$ & $2,1 \mathrm{ha}$ & $\begin{array}{l}2 \\
3 \\
4\end{array}$ & Piedra, ladrillos & $\begin{array}{l}\text { Ataifores, redomas, } \\
\text { lebrillos, tinajas, cazuelas, } \\
\text { marmitas, tapaderas, } \\
\text { Jarros, jarritas }\end{array}$ & $\begin{array}{l}\text { "Alta" } \\
\text { "Mayor proporolón de } \\
\text { cerámica de cocina- } \\
\text { mesa que de cerámica } \\
\text { de almacenamiento" }\end{array}$ & Escorias de metal & Rodriguet, 2010 \\
\hline $\begin{array}{l}\text { El Castillejo } \\
\text { (Los Guajares. } \\
\text { Granada) }\end{array}$ & $E$ & $1,56 \mathrm{ha}$ & $\begin{array}{l}1 \\
2 \\
3 \\
4\end{array}$ & $\begin{array}{l}\text { Tégulas, piedra, } \\
\text { tapial }\end{array}$ & $\begin{array}{c}\text { Cazuelas, marmitas, } \\
\text { cuscuseras, discos, jarras, } \\
\text { tinajas, cono de azucar, } \\
\text { lebrillos, candiles, anafes, } \\
\text { ataifores, jarritas, jarros, } \\
\text { copas, botellitas, redomas, } \\
\text { atabal, fichas, } \\
\text { cantimploras, tapaderas, } \\
\text { reposaderos }\end{array}$ & $\begin{array}{c}422 \text { piezas } \\
\text { identificadas } \\
\text { Ceraimica de mesa } \\
\text { cocina ( } 57,85 \%) \\
\text { Ceramica de } \\
\text { almacenamiento } \\
\text { (20,99\%) }\end{array}$ & $\begin{array}{l}\text { Estructuras hidráulicas de } \\
\text { regadio, alijibe, torres, muralla, } \\
\text { restos de casas, calles, monedas }\end{array}$ & $\begin{array}{c}\text { Malpica et ali, } 1987 \\
\text { Cressier, Malpica y Rossello, } \\
1987 \\
\text { Malpica y Cressier, } 1991 \\
\text { Garcia Porras, } 2001 \\
\text { Garcia Porras, } 2007\end{array}$ \\
\hline $\begin{array}{l}\text { Los Hiniestares } \\
\text { (Castril, Granada) }\end{array}$ & $P$ & ¿? & $\begin{array}{l}1 \\
3\end{array}$ & Sillares & ¿? & $t^{2}$ & ¿Aperos?, ćacequia? & Malpica, 2000 \\
\hline $\begin{array}{c}\text { Cebas } \\
\text { (Castrii, Granada) }\end{array}$ & P & d? & $\begin{array}{l}1 \\
2 \\
3\end{array}$ & ¿? & d? & ¿? & c? & Malpica, 2006 \\
\hline $\begin{array}{c}\text { Lezas } \\
\text { (Castril, Granada) }\end{array}$ & $P$ & c? & $\begin{array}{l}1 \\
2 \\
3\end{array}$ & ¿? & ¿? & ¿? & ¿? & $\begin{array}{l}\text { Malpica, } 2000 \\
\text { Malpica, } 2006\end{array}$ \\
\hline $\begin{array}{l}\text { Arboleas } \\
\text { (Huércal-Owera, } \\
\text { Almeria) }\end{array}$ & P & E) ha & ¿? & ¿? & ¿? & ह? & $\begin{array}{l}\text { Torre tardoandalusi-morisca, } \\
\text { aljibe, restos de muros }\end{array}$ & Cressier, $1990 \mathrm{~b}$ \\
\hline $\begin{array}{c}\text { Campana } \\
\text { (Purchena, } \\
\text { Almeria) }\end{array}$ & P & ¿?ha & $d ?$ & ¿? & $d ?$ & ¿'? & 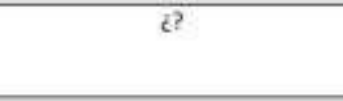 & Cressier, $1990 \mathrm{~b}$ \\
\hline $\begin{array}{l}\text { Albánchez } \\
\text { (Albánchez, } \\
\text { Almeria) }\end{array}$ & P & ¿? ha & $\begin{array}{l}2 \\
3\end{array}$ & ¿? & ¿? & "Bastante rica" & $\begin{array}{l}\text { Restos de muros, ajibe, reducto } \\
\text { defensivo (ctorre?) }\end{array}$ & Cressier, 1987a \\
\hline $\begin{array}{l}\text { Alhabia } \\
\text { (Alcudia de } \\
\text { Monteagud, } \\
\text { Almeria) }\end{array}$ & P & Elha & $\begin{array}{l}2 \\
3\end{array}$ & Pizarra & ¿? & "Abundante" & $\begin{array}{l}\text { Torre de alqueria, sistema } \\
\text { hidraulico de regadio }\end{array}$ & $\begin{array}{l}\text { Cressier, } 1987 \mathrm{a} \\
\text { Cressier, } 1987 \mathrm{~b}\end{array}$ \\
\hline $\begin{array}{l}\text { Torre de los } \\
\text { Casarazos/ } \\
\text { Despobiado de } \\
\text { Benalguaciles } \\
\text { (Alcudia de } \\
\text { Monteagud, }\end{array}$ & $P$ & 27 ha & 2 & Esquisto & 27 & "Escass" & $\begin{array}{c}\text { Restos de muros, ¿torre de } \\
\text { alqueria? }\end{array}$ & Cressier, $1987 \mathrm{~b}$ \\
\hline
\end{tabular}




\begin{tabular}{|c|c|c|c|c|c|c|c|c|}
\hline Almería) & & & & & & & & \\
\hline $\begin{array}{l}\text { Benimina } \\
\text { (Benizalòn, } \\
\text { Almeria) }\end{array}$ & p & ? ha & $\begin{array}{l}1 \\
2 \\
3\end{array}$ & Piedra, tapial & ¿? & $\begin{array}{l}\text { "Casi ausencia en el } \\
\text { fortin" } \\
\text { "Muy abundante en el } \\
\text { poblado" }\end{array}$ & $\begin{array}{l}\text { Fortaleza con torre, poblado con } \\
\text { torre de alqueria, muros de } \\
\text { casas, pequeño castillo, poros, } \\
\text { sistema hidraulico de regadio }\end{array}$ & $\begin{array}{l}\text { Cressier, } 1987 \mathrm{a} \\
\text { Cressier, } 1987 \mathrm{~b}\end{array}$ \\
\hline $\begin{array}{c}\text { Benitorafe } \\
\text { (Tahal, Almeria) }\end{array}$ & $\mathrm{p}$ & E? ha & ¿? & Piedra & ह? & $c^{7}$ & Torre de alqueria & $\begin{array}{l}\text { Cressier, } 1987 a \\
\text { Cressier } 1987 b\end{array}$ \\
\hline $\begin{array}{c}\text { Sufli } \\
\text { (Cantoria, } \\
\text { Almeria) }\end{array}$ & p & c? ha & ¿? & $c^{7}$ & $\vec{c} ?$ & $c^{?}$ & Torre de alqueria & Cressier, 1987a \\
\hline $\begin{array}{l}\text { Torre de Medalia } \\
\text { (Tahal, Almeria) }\end{array}$ & $p$ & E7 ha & 5 & Piedra, pizarra & ¿? & "Abundante" & $\begin{array}{l}\text { Recinto murado, ¿torre de } \\
\text { alquerias, despoblado }\end{array}$ & Cressier, 1987b \\
\hline $\begin{array}{l}\text { La Torrecica } \\
\text { (Zurgena, } \\
\text { Almeria) }\end{array}$ & $p$ & $\begin{array}{c}\text { "Superior a } 1 \\
\text { ha" }\end{array}$ & $\begin{array}{l}1 \\
3\end{array}$ & Tapial & $\iota^{2}$ & "Abundante" & Restos de muros & Cressier, 1991b \\
\hline $\begin{array}{c}\text { Torre Negra } \\
\text { (Senés, Almeria) }\end{array}$ & P & d?ha & 5 & ह? & ¿? & ह? & Torre de alqueria & Cressier y Delaigue, 1992 \\
\hline $\begin{array}{c}\text { El Moratón } \\
\text { (Seness; Almeria) }\end{array}$ & p & d? ha & 3 & ह? & ¿? & "Abundante" & $\begin{array}{l}\text { ¿Torre de alqueria?, estructuras } \\
\text { hidráulicas }\end{array}$ & Cressier y Delaigue, 1992 \\
\hline $\begin{array}{l}\text { Los Zarzales } \\
\text { (Cañada de la } \\
\text { Petaca, Almenla) }\end{array}$ & $p$ & E? ha & 4 & Ladrillos, pledra & $e^{?}$ & "Abundante" & Restos de muros, silos, tumbas & Cressier y Delaigue, 1992 \\
\hline $\begin{array}{l}\text { Les Perales } \\
\text { (Senés, Alimeria) }\end{array}$ & $p$ & E?ha & $\begin{array}{l}1 \\
3\end{array}$ & ¿? & ¿? & $\begin{array}{l}\text { "Presencia de } \\
\text { cerámica" }\end{array}$ & $\begin{array}{l}\text { Restos de muros, tumbas, } \\
\text { estructuras hidraulicas }\end{array}$ & Cressier et alit, 1993 \\
\hline $\begin{array}{c}\text { Cuesta Roca } \\
\text { (Senes, Almeria) }\end{array}$ & $\begin{array}{l}P \\
E\end{array}$ & $\begin{array}{l}\text { ¿? ha } \\
0,0045 \text { ha } \\
\text { excavadas }\end{array}$ & $\begin{array}{l}1 \\
3\end{array}$ & Piedra & $2 ?$ & $\begin{array}{l}\text { "Abundante en } \\
\text { superficie" }\end{array}$ & $\begin{array}{l}\text { Restos de casas, silos, tapadera } \\
\text { de tinaja de esquisto, pesa de } \\
\text { telar de pizarra, vidrio de colores } \\
\text { (vasos, pulseras) }\end{array}$ & $\begin{array}{c}\text { Cressier, 1990a } \\
\text { Cressier, 1990b } \\
\text { Cressier y Delaigue, } 1992\end{array}$ \\
\hline $\begin{array}{l}\text { La Hioya } \\
\text { (Cantoria, } \\
\text { Almeria) }\end{array}$ & $\begin{array}{l}P \\
E\end{array}$ & c? & 1 & $\begin{array}{l}\text { Piedra, pizarra, } \\
\text { columnillas de } \\
\text { marmol }\end{array}$ & $\begin{array}{l}\text { Jarritas, redomas, tinajas, } \\
\text { cazuela, marmita, } \\
\text { tapadera, botella, candit, } \\
\text { ataifores, jarros }\end{array}$ & $\begin{array}{l}\text { "Abundante en } \\
\text { superficie" }\end{array}$ & $\begin{array}{l}\text { Restos de casas, huesos, hogat, } \\
\text { vidrio (botellitas, pulseras). } \\
\text { piezas de cobre, sepulturas }\end{array}$ & $\begin{array}{c}\text { Cressier, 1990a } \\
\text { Cressier, 1990b } \\
\text { Cressier et alii, } 1993\end{array}$ \\
\hline $\begin{array}{c}\text { Bofilla } \\
\text { (Bétera, Valencia) }\end{array}$ & Epr & 4 ha & $\begin{array}{l}1 \\
3 \\
4\end{array}$ & $\begin{array}{l}\text { Tapial, piedra, tejas, } \\
\text { ladrillo, teselas, } \\
\text { tégulas, gozne de } \\
\text { puerta de piedra, } \\
\text { enlucido de cal }\end{array}$ & $\begin{array}{l}\text { Ataifores, jofainas, } \\
\text { cuscusero, jarras/os, } \\
\text { jarritas/os, redomas, } \\
\text { caintaros, cazuelas, ollas, } \\
\text { morteros, onzas, tinajas, } \\
\text { lebrillos, tripodes, } \\
\text { tapaderas, arcaduces, } \\
\text { candiles, macetas, } \\
\text { alfabeguer }\end{array}$ & $\begin{array}{l}\text { En Guichard, 1976: } \\
\text { Más de 2.500 } \\
\text { fragmentos } \\
\text { Predominio de } \\
\text { cerámica comün } \\
\text { bizcochada o vidriada } \\
\text { En Lòpez, 1994: }\end{array}$ & $\begin{array}{l}\text { Restos de casas, torre de } \\
\text { alqueria, albacar, muralla, bahios, } \\
\text { calles, pozos, enterramientos, } \\
\text { monedas, hornos, agujas, } \\
\text { utensilios de hueso, anillos, } \\
\text { sortijas, clavos, espatulas, } \\
\text { hebillas, uttiles de hierro, piezas } \\
\text { de telares, huesos de } \\
\text { ovicápridos, trocitos de hierro, } \\
\text { bolita de marfil }\end{array}$ & $\begin{array}{l}\text { Guichard, } 1976 \\
\text { Lopez, } 1994 \\
\text { Guichard, } 2006\end{array}$ \\
\hline
\end{tabular}




\begin{tabular}{|c|c|c|c|c|c|c|c|c|}
\hline & & & & & & $\begin{array}{l}24.000 \text { fragenentos en } \\
\text { total } \\
18.000 \text { fragmentos de } \\
\text { ceramica común no } \\
\text { barmizada ni decorada }\end{array}$ & & \\
\hline $\begin{array}{l}\text { Font Voltà } \\
\text { (Ares del } \\
\text { Maestrat, } \\
\text { Castellon) }\end{array}$ & $\begin{array}{l}\mathrm{E} \\
\mathrm{p}\end{array}$ & $\begin{array}{l}\text { ¿? ha } \\
\text { "Pequenta" } \\
\text { Algo más de } \\
0,009 \text { ha } \\
\text { excavadas }\end{array}$ & $\begin{array}{l}1 \\
2 \\
3 \\
4\end{array}$ & $\begin{array}{l}\text { Bloques y losas de } \\
\text { piedra }\end{array}$ & d? & $\begin{array}{l}\text { "Predominio de } \\
\text { ollas/jarras" }\end{array}$ & $\begin{array}{l}\text { Restos de casas, cobertizo, } \\
\text { objetos de hierro (cuchilio, clavo. } \\
\text { laya, punzón), escoriass de } \\
\text { funditär de hierro, hogar, } \\
\text { mortero de piedra, sistema } \\
\text { hidráulico de irrieación, } \\
\text { yacimiento de hierro próximo }\end{array}$ & González, 1995 \\
\hline $\begin{array}{l}\text { Beniham } \\
\text { (Burriana, } \\
\text { Castelión) }\end{array}$ & $\begin{array}{l}E \\
p\end{array}$ & $\begin{array}{l}\text { L7ha } \\
0.2 \text { ha } \\
\text { excavadas }\end{array}$ & $\begin{array}{l}1 \\
4\end{array}$ & $\begin{array}{l}\text { Ladrillos, tejas, } \\
\text { piedra, cantos de } \\
\text { rio, tapial }\end{array}$ & $\begin{array}{l}\text { Ollas, cazuelas, platos, } \\
\text { ataifores }\end{array}$ & "Abundante" & $\begin{array}{l}\text { Sistema hidriulico de irrigación, } \\
\text { necrópolis, restos de viviendas, } \\
\text { balsas o depositos de arrea fabril, } \\
\text { piedras de molino, barkos, silo, } \\
\text { hornos, huesos de équidosy } \\
\text { ovicapridos }\end{array}$ & $\begin{array}{l}\text { Benedito y Melchor, } 2000 \\
\text { Melchor y Benedito, } 2003\end{array}$ \\
\hline $\begin{array}{l}\text { Villa Vieja } \\
\text { [Calasparra. } \\
\text { Murcia) }\end{array}$ & $\underset{E P ?}{E}$ & $\begin{array}{l}\text { "0,55 ha" } \\
0,17 \text { ha } \\
\text { excavadas }\end{array}$ & $\begin{array}{l}1 \\
3 \\
4\end{array}$ & $\begin{array}{l}\text { Piedra, tapial, tejas, } \\
\text { cantos de ría. }\end{array}$ & Tinaja, otras $[2 ?]$ & "Abundante" & $\begin{array}{l}\text { Salinas en el entorno, } \\
\text { enterramientos, restos de casas, } \\
\text { muralla, torres, calles, hogares, } \\
\text { silos, alacena, tosas septicas, } \\
\text { vidrio, restos de animales, poro }\end{array}$ & Poro, 2000 \\
\hline $\begin{array}{c}\text { Puentes } \\
\text { (Lorca, Murcia) }\end{array}$ & $\begin{array}{l}P \\
E\end{array}$ & $\begin{array}{l}0,15 \text { ha } \\
\text { (sector B) } \\
0,02643 \text { ha } \\
\text { excavadas }\end{array}$ & $\begin{array}{l}1 \\
2 \\
3\end{array}$ & $\begin{array}{l}\text { Piedra, adobe, } \\
\text { pizarra }\end{array}$ & $\begin{array}{l}\text { Ataifores, candiles, } \\
\text { marmitas, cazuela, } \\
\text { cuscusera-quesera, anafe, } \\
\text { brasero, tapaderas, platos } \\
\text { para caces pan, alcadafes, } \\
\text { jarros, tinaja jarritas, } \\
\text { jofainas, cuencos, redomas. }\end{array}$ & "Escasos" & $\begin{array}{l}\text { Restos de casas, enterramientos, } \\
\text { ¿mezquita doméstica?, pledras } \\
\text { de molino, vidrio, clavos, lañuss, } \\
\text { puñal, punta de flecha, púa, } \\
\text { monedas, escoria de metal }\end{array}$ & $\begin{array}{l}\text { Pujante, } 2002 \\
\text { Pujante, } 2006\end{array}$ \\
\hline $\begin{array}{l}\text { Molina de la } \\
\text { Venta } \\
\text { (Lorca, Murcia) }\end{array}$ & $\begin{array}{l}P \\
E\end{array}$ & $z^{2}$ & $\begin{array}{l}1 \\
3 \\
4 \\
5 \\
\end{array}$ & ¿? & 27 & d? & 27 & Pujante, 2002 \\
\hline $\begin{array}{l}\text { El Cortijo del } \\
\text { Centeno } \\
\text { (Lorca, Murcia) }\end{array}$ & $\begin{array}{l}\text { E } \\
\text { P }\end{array}$ & $\begin{array}{l}\text { ¿? ha } \\
\text { Algo más de } \\
0.0196 \text { ha } \\
\text { excavadas }\end{array}$ & $\begin{array}{l}1 \\
-3 \\
4\end{array}$ & $\begin{array}{l}\text { Piedra, ladrillos, } \\
\text { tapial; adobe, } \\
\text { cantos rodados, } \\
\text { pizarra }\end{array}$ & i? & "Gran cantidad" & $\begin{array}{l}\text { Mezquáta, pileta de abluciones, } \\
\text { camalización, enterramientos, } \\
\text { restos de casas, hornos, hogares, } \\
\text { fragmentos de molino, braseros }\end{array}$ & $\begin{array}{l}\text { Pujante, } 2000 \\
\text { Pujante, } 2002\end{array}$ \\
\hline
\end{tabular}

NOTAS

- Técnica de documentación: E.- Excavación arqueológica. P.- Prospección arqueológica.

- Caracteristicas del emplazamiento: 1-Cercania de un cauce de agua. 2-Proximidad a un barranco, escarpe o peñón. 3- Elevación del terreno. 4-Proximidad a vía de comunicación. 5.- Terreno llano o casi llano.

- Algunas de las cantidades porcentuales relativas a la densidad de los tipos cerámicos han sido estimadas por nosotros. 
